\title{
The time-dependence of electromagnetic response functions
}

\author{
Beamish, D. 1982. The time-dependence of electromagnetic response functions. Geophys. Surveys, \\ 4, 405-434. \\ DOI: 10.1007/BF01449109
}

\author{
Geomagnetism Unit, Institute of Geological Sciences, Murchison House, West Mains Road, \\ Edinburgh, EH9 3LA, UK.
}

\begin{abstract}
Dynamic processes within the Earth are capable of modifying many of its physical properties. This review considers the modification of electrical resistivity mainly by time-changes in the stressfield experienced by crustal materials. Laboratory experiments indicate that certain rock types, whose resistivity is controlled by the volume and geometry of microcracks, can undergo large resistivity variations in response to the typical strain accumulation and release that accompanies major earthquakes. Electromagnetic response functions are reviewed with regard to their ability to monitor timechanges of resistivity in active regions. Some examples of the different experimental techniques used to investigate precursory changes in response functions prior to earthquakes are noted. The problems and successes of the subsequent cotrelation and interpretation of the derived response as a function of time are then discussed. Only relatively few controlled and integrated studies of time-dependent electromagnetic response functions exist. Those which are available, however, emphasise that changing stress-differentials occurring before major earthquakes can be monitored using suitable electromagnetic techniques.
\end{abstract}

\section{Introduction}

The Earth we are considering in the present review is a crust and upper mantle heavily permeated by cracks. Both sedimentary and igneous rocks have a variety of microcracks within grains and along grain boundaries (Simmons and Richter, 1976). The cracks within igneous rocks may remain open for some distance into the upper mantle if the pore pressures are large enough (Brace, 1972). Under purely hydrostatic pressure these various cracks will stay closed. Dynamic Earth processes, however, produce differential stress regimes which ultimately lead to the different characteristic tectonic zones. The action of such stress is capable of both opening and closing such cracks causing changes in many physical properties. The effect of changing stress on both local magnetic field and electrical resistivity has already been well-documented by laboratory studies. This review considers these effects and the observations of time dependent electromagnetic response functions which appear capable of monitoring such processes in active tectonic situations.

At the outset we must acknowledge two stress-induced effects in relation to electromagnetic studies:

(a) Changes in local magnetic field.

(b) Changes in electrical resistivity.

Within a given tectonic zone, both effects might well be observed. However, most studies to date have involved either (a) or (b). The study of (a) has had a longer history and it is now possible to review some of the observations in terms of their particular tectonic setting. This is undertaken in a complementary review presented by Dr J. C. Rossignol.

This review concerns itself with subject matter relating to (b) and the possibilities of 
monitoring the effects of dynamic Earth processes by their effects on electrical resistivity. The subject had its first Workshop Review in Murnau (1978) when Niblett and Honkura were the reviewers.

\section{Stress-Strain Effects on Electromagnetic Phenomena}

We begin by noting several terms widely quoted in the literature and their original and adopted meanings:

Seismomagnetic (see Stacey, 1963)

An investigation of the magnetic behaviour accompanying earthquakes (ie behaviour preand post-energy release) with a view to understanding the correlation and/or precursory nature of the magnetic effects.

Tectonomagnetic (see Nagata, 1969)

A long-term monitoring of the magnetic field (e.g. in the vicinity of a fault) to detect changes in the magnetic field due to general tectonic activity and crustal stress accumulation with a view to understanding earthquake mechanisms.

Vulcanomagnetic (see Stacey et al., 1965)

A special case of the tectonomagnetic effect when the tectonic process is vulcanological.

It is not the purpose of this review to consider observations of these 3 magnetic effects as they are discussed in detail by Dr Rossignol in a parallel review of the subject. It is however worth noting a further electrical effect termed:

Electrokinetic (see Mizutani et al., 1976; Fitterman, 1979)

This effect is caused by fluid motion due to stress differentials within the crust. Fluid, forced through a porous medium, is capable of producing an electrokinetic charge separation. The resulting potential difference (termed a streaming potential) then causes current to flow.

\subsection{STRESS-STRAIN EFFECTS ON THE LOCAL MAGNETIC FIELD}

A change in local magnetic field due to a changing stress field results from the piezomagnetic properties of rocks, i.e. a change in magnetisation due to a change in applied stress. The stress-induced change in magnetic moment $(J)$ can be expressed as:

$$
\Delta \mathrm{J}=\Delta \mathrm{x} H+\Delta(\mathrm{NRM})+\mathrm{PRM}
$$

where $\Delta \chi$ is the change in susceptibility, $H$ is the applied field, $\Delta(\mathrm{NRM})$ is the change in the remnant and PRM is the acquired pressure remnant moment, Nulman et al. (1978) consider the effects of hydrostatic pressure on the susceptibility of magnetite. Much more work has involved the effects of uniaxial stress on the component parts of (1). Kean et al. (1976) summarise many of the laboratory studies. In general these studies have found that susceptibility parallel to the compression axis decreases while the component trans- 
verse to this axis increases slightly. Figure 1 shows an example of the behaviour of rocks containing magnetic minerals within the elastic range. We observe that the pressure response of both magnetite and titanomagnetite dispersions is a function of grain size of the magnetic material. The results indicate that rocks containing coarse-grained titanomagnetites are the most efficient stress transducers. The above example comes from a study of reversible magnetic changes; Nagata (1969) considers the category of rocks that undergo irreversible magnetic changes.

In relation to the stress-sensitivity of magnetic susceptibility, the numerical studies of Stacey and Johnston (1972) give values in the range 1.11 to $11.5 \times 10^{-4} \mathrm{bar}^{-1}$. The stress sensitivity obtained from the laboratory samples of Kean et al. (1976) give values in the same range. Given the laboratory data together with theoretical support it has been possible to estimate the order of the local magnetic field change $(\Delta F)$ we might expect
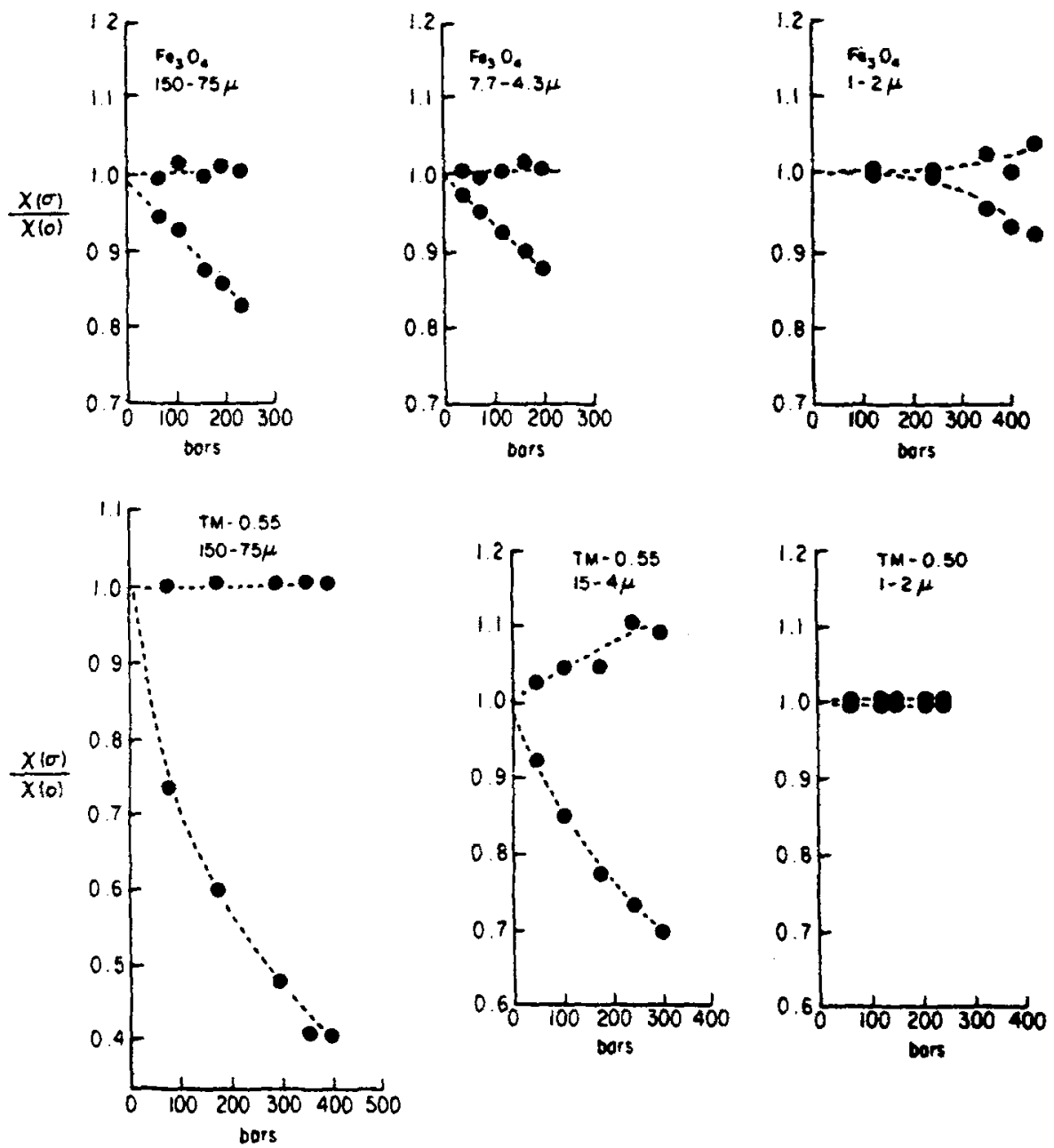

Fig. 1. Changes in magnetic susceptibility with stress of magnetite $\left(\mathrm{Fe}_{3} \mathrm{O}_{4}\right)$ and titanomagnetite (TM) dispersions for 3 different grain sizes (from Kean et al., 1976). 
in tectonically active areas. Studies of this kind (Stacey, 1963, 1964; Yukutake and Tachinaka, 1967) reveal a maximum value of $\Delta F \sim 10 \mathrm{nT}$.

\subsection{STRESS-STRAIN EFFECTS ON ELECTRICAL RESISTIVITY}

The class of rocks that we are examining in time-dependent studies are fault-zone rocks. As Madden (1980) points out, there are virtually no laboratory studies of materials typical of a fault zone. Within fault zones, the main conduction mechanism is due to the presence of water in an interconnected system of pores and cracks within the rock. The actual conductivity depends on 2 factors:

\subsubsection{The Conductivity of the Pore Fluid}

The pore fluid conductivity at upper crustal temperatures and pressures depends on the salinity of the fluid and the temperature. Conductivity is approximately linearly dependent on salinity. The temperature effect is much more variable. We observe a 10 -fold increase in conductivity from 0 to $400{ }^{\circ} \mathrm{C}$, beyond which water loses its ability to dissociate dissolved salts, so the conductivity then decreases as the temperature increases (Madden, 1980).

\subsubsection{The Volume and Geometry of Pores and Cracks}

Stress affects electrical resistivity by opening or closing existing cracks and creating new ones. Most early laboratory studies were done under hydrostatic pressure (Brace et al., 1965). Narrow cracks (low aspect ratio) close with modest pressure so that rocks whose resistivity is dominated by their crack populations show very large resistivity changes at modest pressure. This is typical of the behaviour of low porosity igneous and metamorphic rocks. The resistivity variation is a large amplification of the strain variation.

Brace and Orange $(1966,1968)$ extended their earlier experiments under hydrostatic pressure to include the effect of deviatoric loads ( $\equiv$ stress) on resistivity changes of watersaturated crystalline rocks. Some of the experimental results of Brace and Orange (1968) are reproduced in Figure 2. In general, the resistivity of a saturated rock increases slightly under compression due to crack closure. Between one- and two-thirds of the fracture stress, resistivity decreases rapidly to a value an order of magnitude lower than the original unstressed value. Brace and Orange noted a close correlation between the decrease in resistivity, the decrease of pore pressure and the onset of dilatancy thus arguing that the rapid decrease of resistivity was associated with the new crack formation (or increase in void volume space) that is termed dilatancy. The maximum sensitivity to axial stress reached by these rocks is about $0.05 \%$ bar $^{-1}$. The results of Brace and Orange (1968) for a sandstone (porosity $\sim 3 \%$ ) indicate a resistivity-stress sensitivity equivalent to that of igneous and metamorphic rocks within the dilatant region. For a high porosity sandstone $(\sim 24 \%)$ shear stress has little observable effect on resistivity

It appears that the sensitivity of the electrical properties of rocks to stress-changes depends on the extent to which cracks control the resistivity. Madden (1980) summarises 


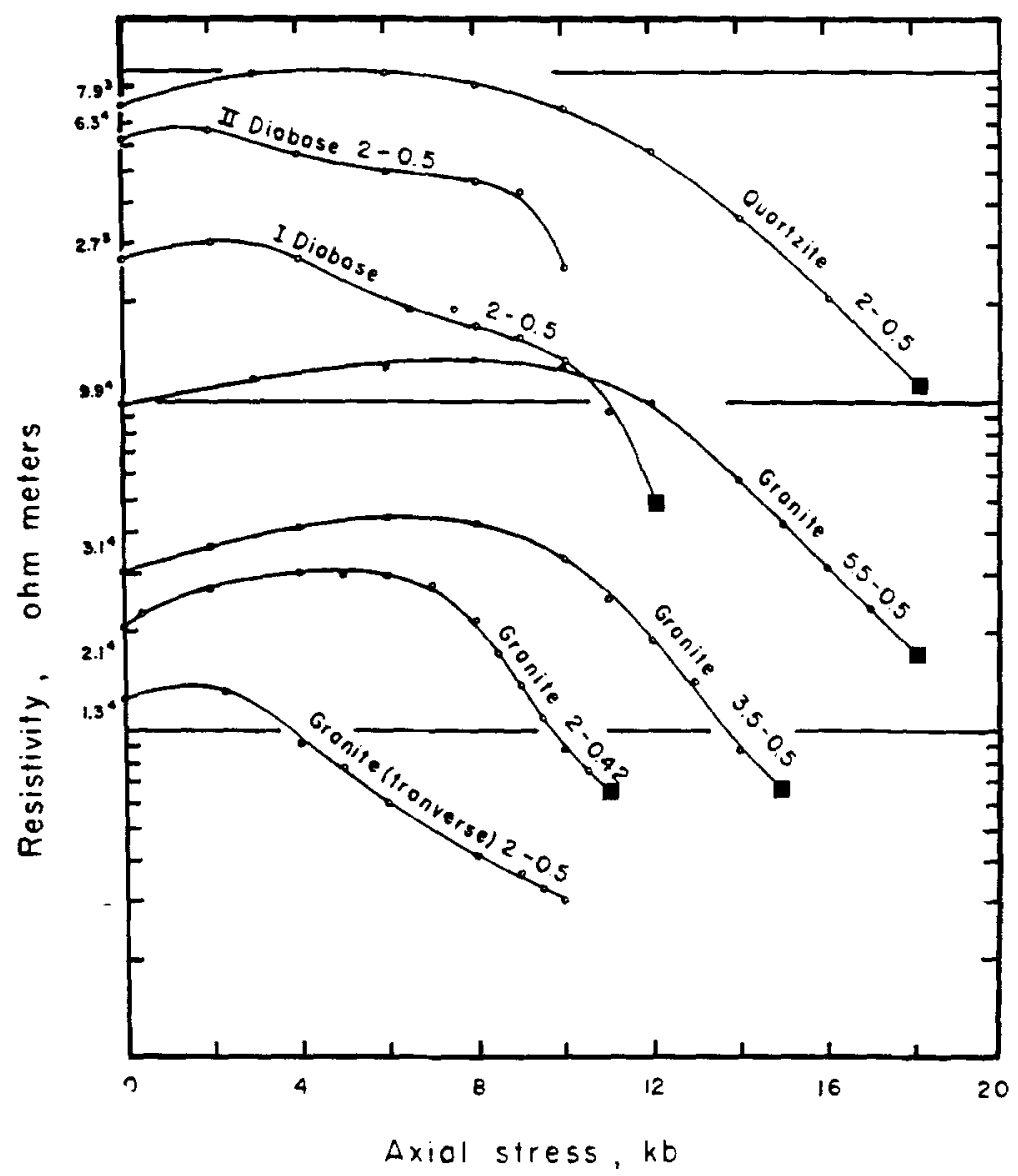

Fig. 2. Resistivity as a function of axial stress. The numbers after the rock name are the confining and pore pressure in kilobars. The curves have been displaced vertically for convenience: $7.9^{3}$ means $7.9 \times 10^{3} \mathrm{ohm}-\mathrm{m}$. All except the bottom curve are resistivity in the axial direction. Fracture occurred at points noted by solid squares (after Brace and Orange, 1968).

a large volume of work undertaken at MIT on resistivity-stress relationships using depth and porosity as parameters. His results are summarised in Table I. The data base is made up of work on igneous, metamorphic and sedimentary rocks. Madden (1980) favours the $3 \%$ porosity rocks as the best estimate we have for the, as yet, unstudied fault zone rocks.

\subsubsection{Dilatancy-diffusion}

As noted above, at high stress nearly all rocks dilate, ie the void volume increases leading to an effective increase in porosity. Earthquake prediction studies were given an effective physical basis by Nur (1972) and Scholz et al. (1973) who took the mechanisms of rock dilatancy and fluid diffusion and found they were able to explain a large class of reported precursory phenomena associated with earthquakes. The dilatancy model is deterministic (cf. probabilistic) and predicts the type of behaviour to be expected in various physical 
TABLE I

A summary of the stress sensitivity of resistivity of igneous, metamorphic and sedimentary rocks from laboratory studies at MIT. The table uses depth and porosity as parameters with the sensitivities being expressed as $\% \Delta \rho /$ bar (from Madden,

1980).

Non-dilatant strain region

\begin{tabular}{|c|c|c|c|c|c|}
\hline & & \multicolumn{4}{|c|}{ Porosity in \% } \\
\hline & & 1 & 3 & 10 & 30 \\
\hline \multirow{4}{*}{$\begin{array}{l}\text { Depth } \\
(\mathrm{km})\end{array}$} & 0 & 0.4 & 0.3 & 0.04 & 0.02 \\
\hline & 1 & 0.2 & 0.15 & 0.04 & 0.02 \\
\hline & 3 & 0.07 & 0.10 & 0.03 & 0.02 \\
\hline & 10 & 0.03 & 0.03 & 0.02 & \\
\hline
\end{tabular}

Dilatant strain region

\begin{tabular}{|c|c|c|c|c|c|}
\hline & & \multicolumn{4}{|c|}{ Porosity in \% } \\
\hline & & 1 & 3 & 10 & 30 \\
\hline \multirow{4}{*}{$\begin{array}{l}\text { Depth } \\
(\mathrm{km})\end{array}$} & 0 & 0.5 & 0.4 & 0.1 & 0.03 \\
\hline & 1 & 0.3 & 0.2 & 0.1 & 0.03 \\
\hline & 3 & 0.1 & 0.10 & 0.05 & 0.03 \\
\hline & 10 & 0.05 & 0.05 & 0.03 & \\
\hline
\end{tabular}

parameters as shown in Figure 3. During stage I, stress is increasing but is below the level required to produce dilatancy. In stage II, dilatant cracks form and become undersaturated and seismic velocity ratios and resistivity respond directly since dilatancy will be accompanied by an influx of water into the dilatant zone. Water diffusion continues through stage III delaying the earthquake by reducing pore pressure on the fault. At the end of stage III the earthquake is triggered when the pore pressure is finally recovered.

In connection with the above we should note that fluid diffusion is enhanced by the increase in permeability associated with the effective increase in porosity during dilatancy. Brace (1978) considers the changes in permeability in sandstone and granite through to failure. The results indicate an increase in permeability of nearly 3-fold in granite at high stress $(>50 \%$ of the fracture stress). 


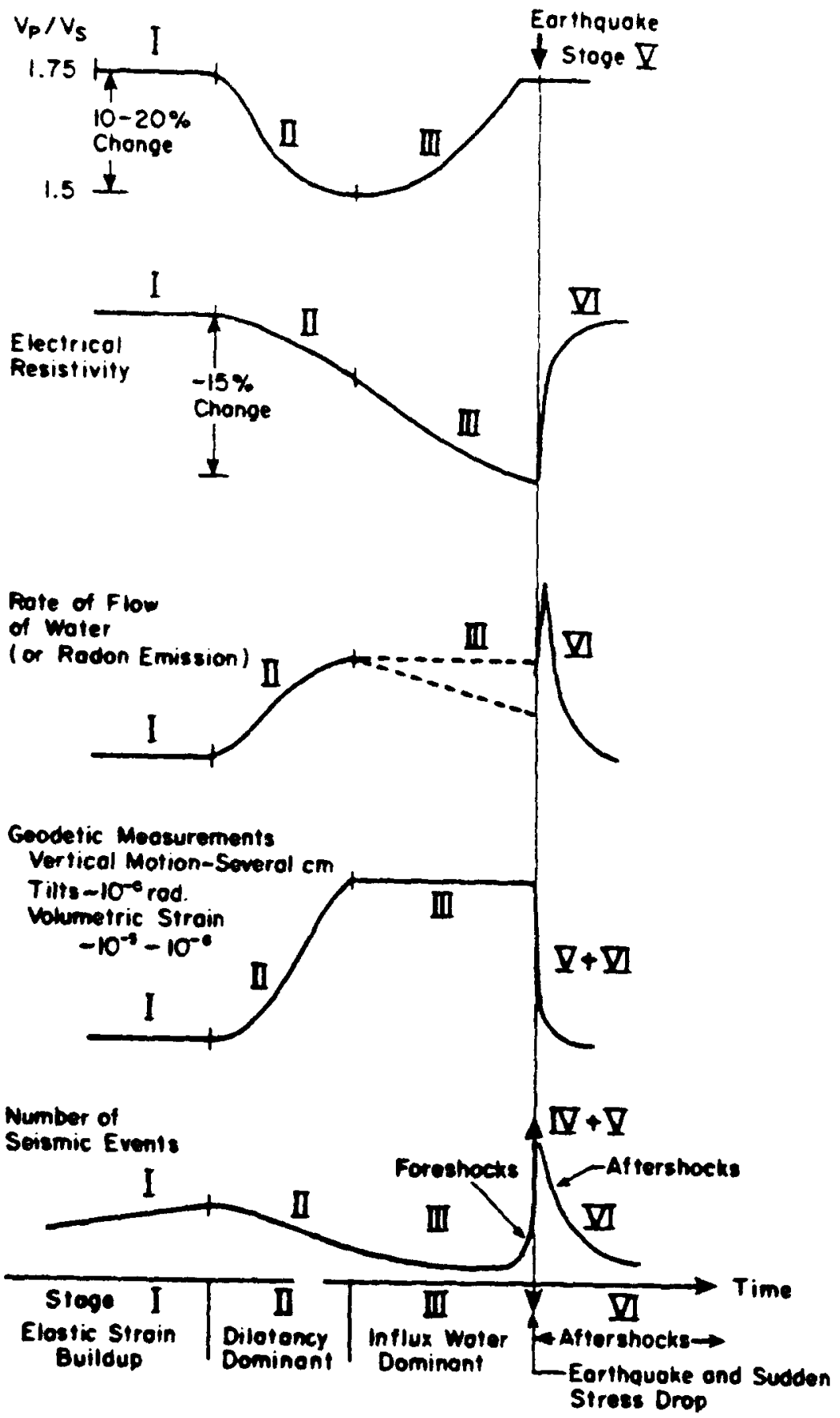

Fig. 3. Changes in various physical parameters as a function of time through the earthquake cycle predicted by the dilatancy-diffusion process (after Sholz et al., 1973). 


\subsubsection{Frictional Sliding and Fracture}

Frictional sliding and fracture within rocks has also been studied with regard to electrical resistivity measurements. Brace and Orange (1966) concluded that, once a fault was formed, further resistivity changes were insignificant. Wang et al. (1975) reported that during stick-slip of saturated granite on sawcut surfaces, changes in resistivity were measurable and significant. The two conflicting results have been reconciled by Wang et al. (1978) who report at least 2 types of change in resistivity during stick-slip. During frictional sliding in finely-ground surfaces of water-saturated granite, the resistivity decreases just before sudden slip but the change is only a few percent. Such a small percentage change would be difficult to detect.

\subsubsection{Summary}

Large changes in resistivity do occur during the fracture of initially intact (competent) rock but the stress-interval over which these changes take place is several kilobars. Readily detectable changes in resistivity occur only after the onset of dilatancy.

Actual observations of stress accompanying the strike-slip San Andreas Fault (Zoback and Roller, 1979; Sbar et al., 1979) indicate an upper limit of 100 bars, well below the stress level required to initiate dilatancy in competent laboratory samples. At the present time, most laboratory work has studied the effect of microcrack (cf. joint) dilatancy. We should note that the stress required to cause dilatancy depends on the aspect ratio of the cracks. When earthquakes occur along well-established faults the relevant cracks are likely to be joints and fractures and the stresses probably remain well below the level necessary to fracture intact rock.

\section{Electromagnetic Response Functions}

This section briefly reviews some of the electromagnetic response functions that have been examined for possible time-dependence. We can first divide e.m. studies into those using active and passive techniques. Direct current methods using controlled source configurations are able to monitor resistivity $(\rho)$ directly by using the expression $\rho=E / I$. Little or no processing of the response function $(\rho)$ is required by such methods and it is worth noting that although many of these techniques obtain a scalar response function, they have been the most successful in demonstrating resistivity changes associated with earthquakes.

The response functions deriving from passive techniques have also been studied for possible time-dependence. Electromagnetic induction within the Earth implies a linear dependence between electric and magnetic variation fields at a particular frequency. The single station geomagnetic transfer function uses the linear relation between the 3 field components recorded at a single site $(S)$ :

$$
H_{Z}^{S}=A H_{X}^{S}+B H_{Y}^{S}
$$


Where a suitable reference station exists, it is possible to relate the recorded field components to those at a reference site $(R)$ :

$$
\begin{aligned}
& H_{X}^{S}=C H_{X}^{R}+D H_{Y}^{R} \\
& H_{Y}^{S}=E H_{X}^{R}+F H_{Y}^{R} \\
& H_{Z}^{S}=A^{\prime} H_{X}^{R}+B^{\prime} H_{Y}^{R},
\end{aligned}
$$

see for example Schmucker (1970). Expressions (2) and (3) assume that induction by any vertical component of the inducing field is negligible; if this is true then the response functions $(A-F)$ can be regarded as a complete description of anomalous variation fields due to internal concentrations of current in the region of site $S$. The internal current concentrations are provided by lateral variations in geoelectric structure.

The magnetotelluric technique assumes a linear relation between the horizontal components of electric and magnetic variation fields at a particular frequency:

$$
\left(\begin{array}{c}
E_{X} \\
E_{Y}
\end{array}\right)=\left(\begin{array}{cc}
Z_{X X} & Z_{X Y} \\
Z_{Y X} & Z_{Y Y}
\end{array}\right)\left(\begin{array}{c}
H_{X} \\
H_{Y}
\end{array}\right)
$$

Here the response functions (the set of $Z$ 's) are dimensionally equivalent to impedance. In the case of a 1-D layered half-space the diagonal elements $\left(Z_{X X}, Z_{Y Y}\right)$ are zero and we define apparent resistivity $(\rho)$ :

$$
\rho_{X Y}=0.2 T\left|\frac{E_{X}}{H_{Y}}\right|^{2}=0.2 T\left|\frac{E_{Y}}{H_{X}}\right|^{2}=\rho_{Y X}
$$

where $T$ is the period in seconds. For 2 and 3-D structure, the impedance tensor may be rotated to obtain the now complex apparent resistivity in the principal strike directions (Sims et al., 1971).

In order to examine the time dependence in any or all of the response functions noted we must first be sure that the data processing methods used on typical data sets and error determination procedures are valid in the absence of time-dependent crustal processes. We now briefly examine the considerations that are involved in these procedures.

\subsection{DATA PROCESSING AND ERROR DETERMINATION}

When real data are used to estimate the response functions, errors are introduced into the above expressions. The errors are a combination of measurement-noise, signal-processing errors and non-planar inducing fields. All the response-functions from passive experiments must therefore be determined in a statistical sense, usually by least-squares reduction of the errors within the data set. Such procedures should also be capable of providing variance estimates of the resulting response functions. Variance estimators are crucial in the study of time-dependent response functions in order to define a level of confidence in the results obtained. 
The relationships quoted represent 2-input, 1-output linear systems; Goodman (1965) and Bendat and Piersol (1971) give the required confidence-intervals for such systems. Reddy et al. (1976) give an account of the influence of bias (measurement-noise) and random errors on the magnetotelluric response functions. Gamble et al. (1979) have recently discussed the use of remote reference components $(E$ or $H)$ to obtain an unbiased estimate of the impedance tensor. In such circumstances the accuracy with which we can determine the impedance is a function only of random errors. Such an error can be made arbitrarily small by increasing the number of observations. The formulation of Goodman (1965) and Bendat and Piersol (1971) can also be used to place confidence limits on the geomagnetic transfer functions. An alternative, though equivalent, formulation is given by Everett and Hyndman (1967). When $n$ observations of a particular response function, each with its own variance $\left(\sigma_{i}\right)$ are available, a linear regression (with weighting factor $1 / \sigma_{i}$ ) will provide the smallest residual standard deviation of any linear instantaneous method.

\subsection{FREQUENCY CONTENT}

Response functions are usually determined as a sounding curve across a frequency bandwidth determined largely by the frequency response of the magnetic sensors. Ideally, we should examine response functions at frequencies appropriate for sounding mid-to uppercrustal structure. Using skin-depth values as shown in Figure 4, the appropriate period range appears to be 10-0.1s. This is in fact a difficult spectral range to record instrumentally.

Rikitake (1976a) modelled electromagnetic induction in a 2-D rectangular conductor taken to represent a dilatant region in the Earth's crust. Using the appropriate induction parameters it was found that, for the particular model studied, enhancements of the horizontal field of up to $100 \%$ might be expected for short period $(<100 \mathrm{~s})$ events. Honkura (1976) studied the perturbation of a uniform d.c. electric field by shallow and deep conductivity anomalies taken to represent possible dilatant regions within the crust. The model is valid at periods which are sufficiently long to provide a uniform electric field in the crust surrounding the dilatant region. The results suggest that only shallow dilatant regions would be detectable in the perturbed electric field at these periods. Reddy et al. (1976) describe MT measurements in Southern California. Assuming a factor of 5 decrease in resistivity due to a dilatancy-diffusion process, Reddy et al. (1976) model the anticipated change in apparent resistivity pre- and post-dilatancy at 3 sites in terms of an inferred geoelectric structure. The results for the 3 sites are reproduced in Figure 5. The maximum percentage change $(>60 \%)$ for 2 of the sites occurs at periods of $\sim 10 \mathrm{~s}$. The small percentage change at the third site is due to thick $(>18 \mathrm{~km})$ sedimentary cover.

\subsection{SOURCE FIELD CONTRIBUTIONS TO RESPONSE FUNCTIONS}

Although we can, as above, define confidence limits on the response functions, the basic relationships defined in (2) - (4) are based on the assumption that the observed variation fields derive from induction by plane-wave inducing fields. This assumption can be readily called into question at both middle and high geomagnetic latitudes. Many authors have 
Skin depth $=.503\left(\frac{T}{\sigma}\right)^{\frac{1}{2}} \quad \mathrm{~km}$

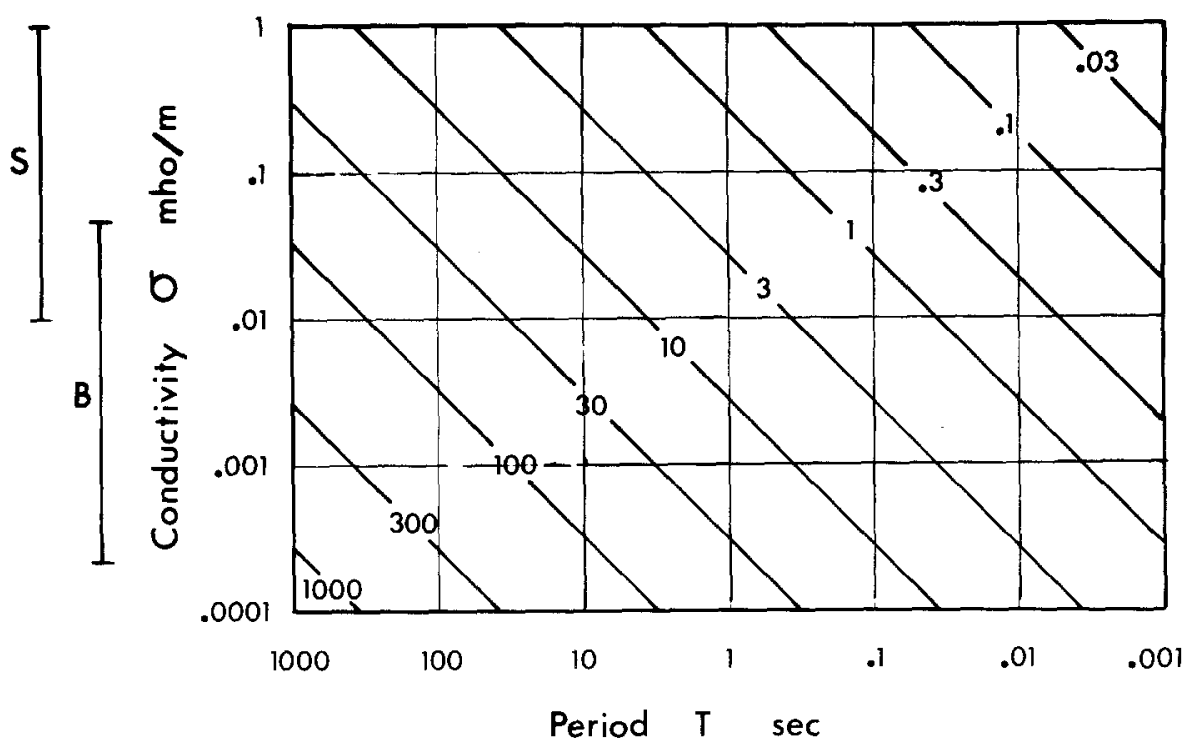

S: Sedimentary B : Basement \& Igneous

Fig. 4. Skin-depth (diagonal lines) for a homogeneous half-space as a function of conductivity and period.

considered the influence of non-planar source fields on electromagnetic measurements. In general, only small deviations (of the uniform source field) occur for penetration depths which are small compared with the wavelength (L) (Srivastava, 1965; Schmucker, 1970). Extreme cases of source localisation occur within the auroral electrojet zone where there is evidence for small-scale structure $(L \sim 250 \mathrm{~km})$ set up by field-aligned currents (see for example, Mersman et al., 1979).

Localised source effects on magnetotelluric apparent resistivities were considered by Quon et al. (1979). The authors considered dipole sources at $100 \mathrm{~km}$ elevation above a simple conductive basin. Such sources would represent the extreme case of source field localisation in the lower ionosphere. The results for a magnetic dipole source were indistinguishable from those due to a planar field at periods less than $50 \mathrm{~s}$ but significant differences occurred at longer periods. The authors comment "Although geomagneticians claim that discrete current systems are unlikely at $100 \mathrm{~km}$ elevation, the question of the sources of scatter in good well smoothed MT results remains to be answered". Figure 6 shows an apparent resistivity curve quoted by Quon et al.(1979). The scatter in the $1-10 \mathrm{~s}$ period band is due to weak signal. However, the boxed cluster around 30-700 s was 

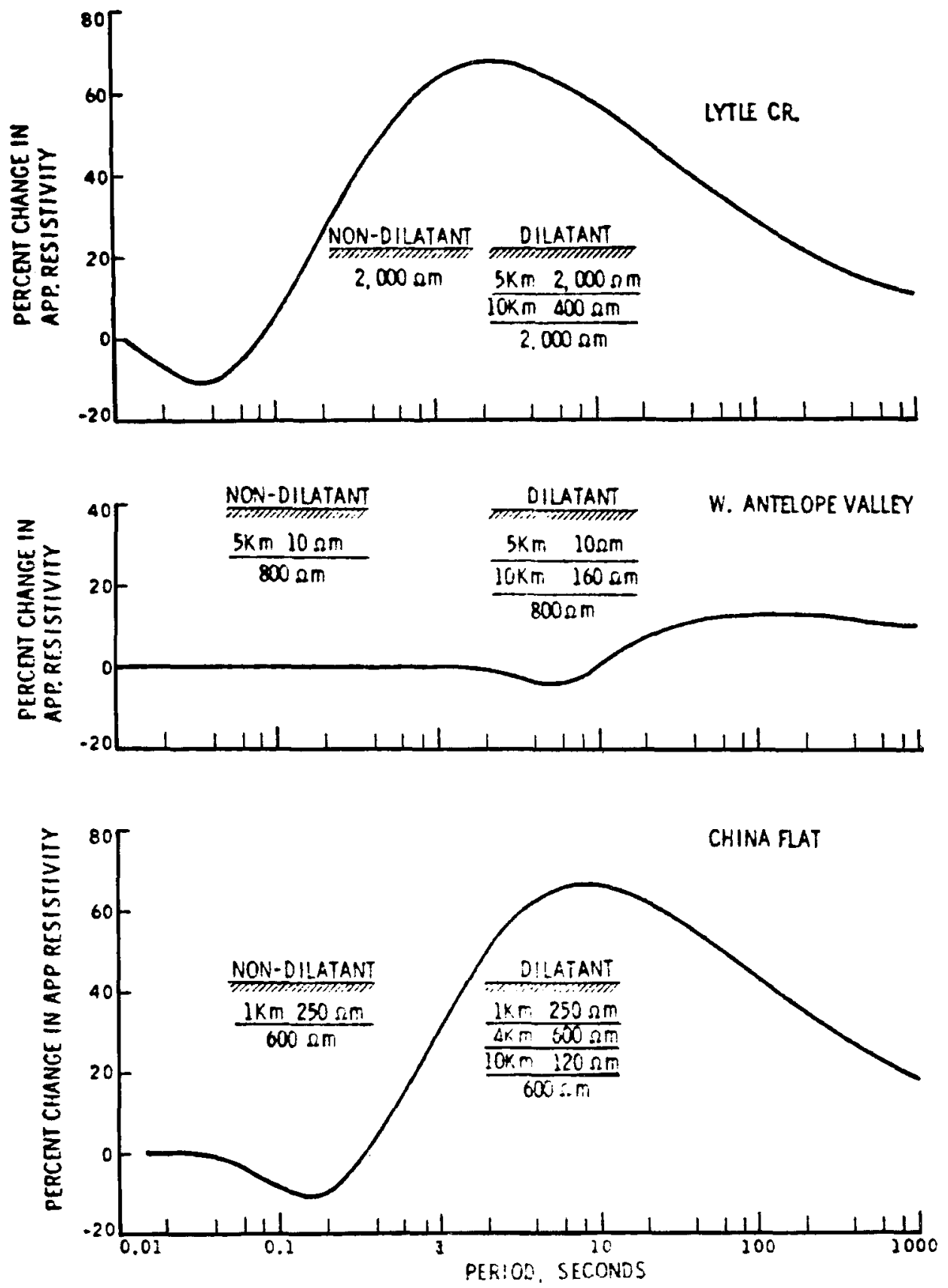

Fig. 5. Anticipated changes in 1-D magnetotelluric apparent resistivities at 3 sites in Southern California due to the inclusion of a crustal dilatant zone (from Reddy et al., 1976). 


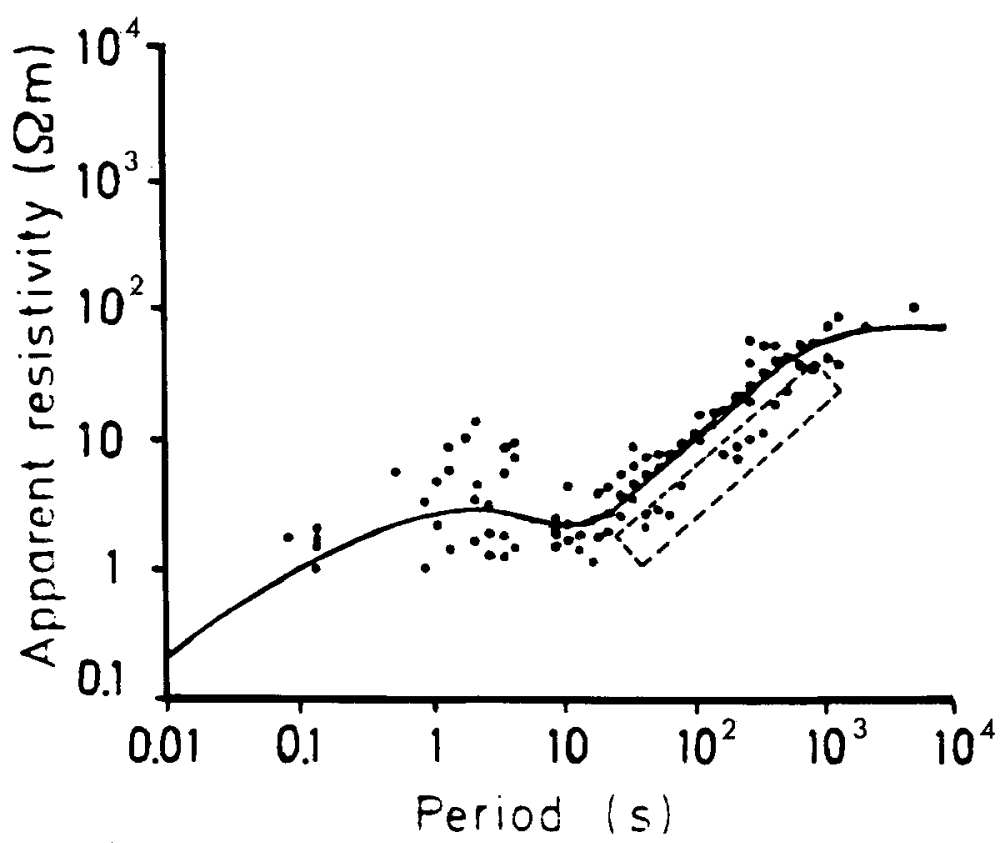

Fig. 6. Rotated tensor apparent resistivity sounding from a sedimentary basin in Central Australia. The boxed estimates were obtained from a single recording and appear to be affected by a localised (ionospheric) source (from Quon et al., 1979).

obtained from a single record at a time of large signal. Using an empirical approach, Beamish (1979) considered the effects of source fields on the geomagnetic transfer function at mid-latitudes in the period range 250-7500 s. Source field effects which increased with both latitude and period were identified. When calculating geomagnetic response functions at substorm periods at both mid-and high-geomagnetic-latitudes it appears necessary to either select data (avoiding data extremes) or to provide a sufficient quantity of data so that a regression procedure may be employed, thus minimising extremes due to source field effects within the data set.

A similar, though distinct, problem appears to arise when geomagnetic transfer functions are obtained in the period range of pulsations (10-500 s). Anderson et al. (1978) studied the local time variation of induction vectors (deriving from $(A, B)$ ) in the period range 37-1380 s. When the 2-h LT determinations were averaged over 12 days of data with the local time dependence retained, diurnal effects in the induction vector were observed. Beamish (1980) further studied the diurnal characteristics of $(A, B)$ at UK latitudes within the pulsation bandwidth and observed significant local time variations. To illustrate the extent of the problem, Figure 7a shows the local time behaviour of $|A|$ and $|B|$ determined at a station in the centre of a magnetometer array operated in the UK. Twelve $2-h$ LT estimates of the transfer function are shown for 5 period bands. The LT variations are compared with the time-averaged estimate which is superimposed as 2 horizontal lines representing \pm 2 s.d. about the mean. At periods greater than $90 \mathrm{~s}$ (B10, B12), no signi- 
$|A|$
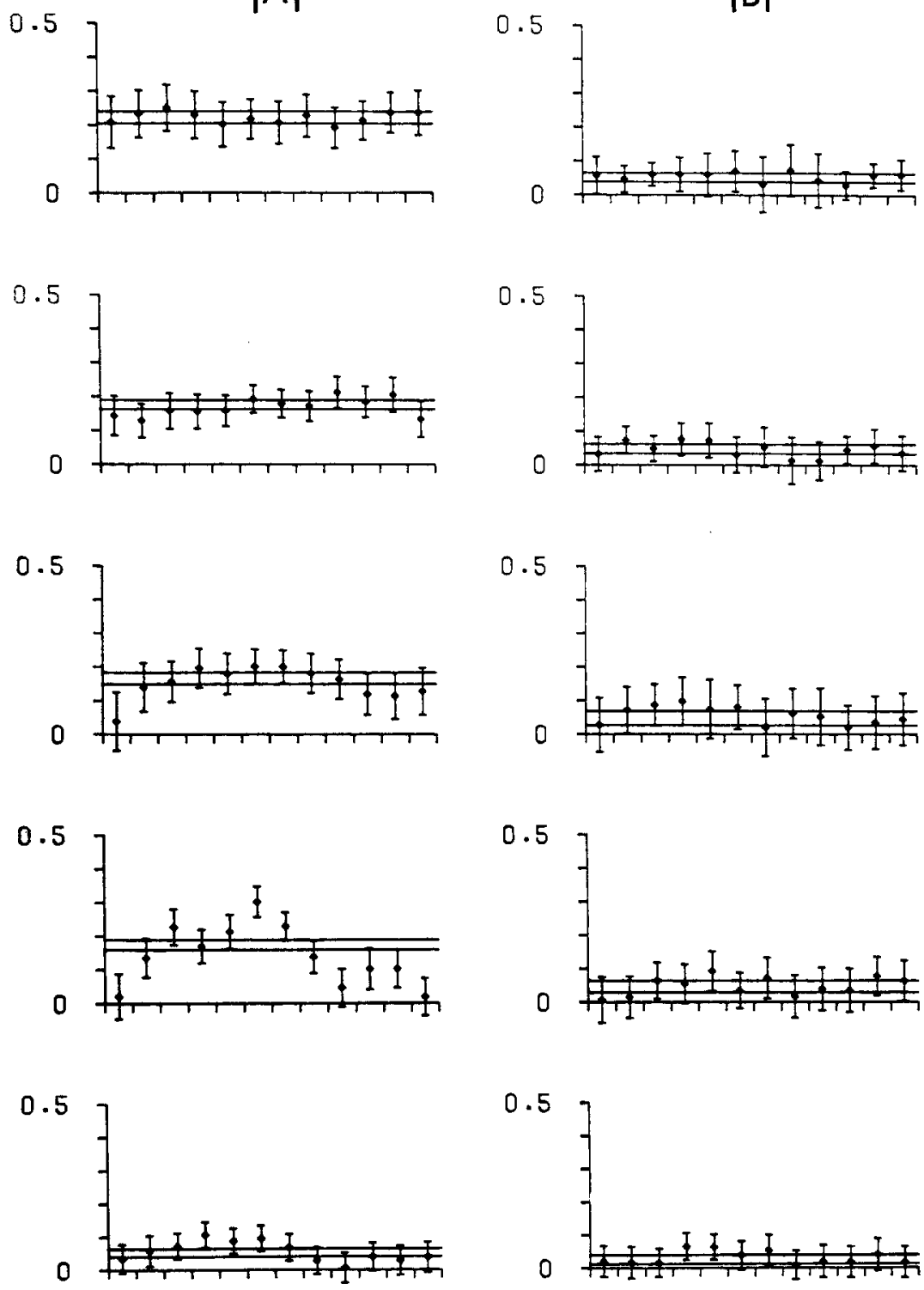

B 14

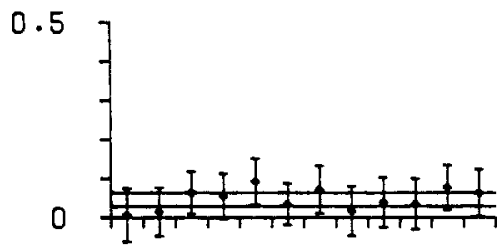

B 16

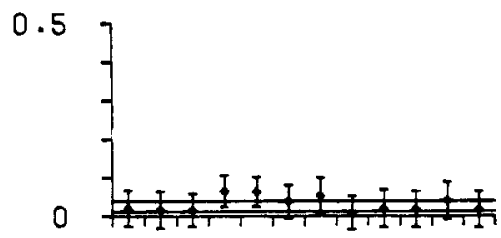

B 18

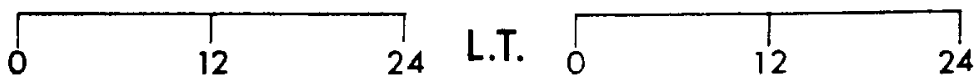

Fig. 7a. Transfer function estimates as a function of local time (LT) from a site in Northern England. Period bands are B10:400-200 s, B12: 200-90 s, B14: 80-60 s, B16: 60-40 s, B18: 40-20 s. Error bars are 4 s.d. in length. 
ficant LT behaviour is observed. However, particularly for periods of 40-60 s (B16) we observe a significant and substantial diumal variation in $|A|$. To illustrate the difficulties still further, the corresponding results for Real $[A]$ in the period range 40-60 s (B16) for 9 stations are shown in Figure $7 \mathrm{~b}$. The separation between successively numbered stations is $\sim 10 \mathrm{~km}$. It seems clear that the LT behaviour is a function of locality. Until such effects are fully understood it seems necessary to exercise some degree of caution when examining other possible time variations in transfer functions at pulsation periods.
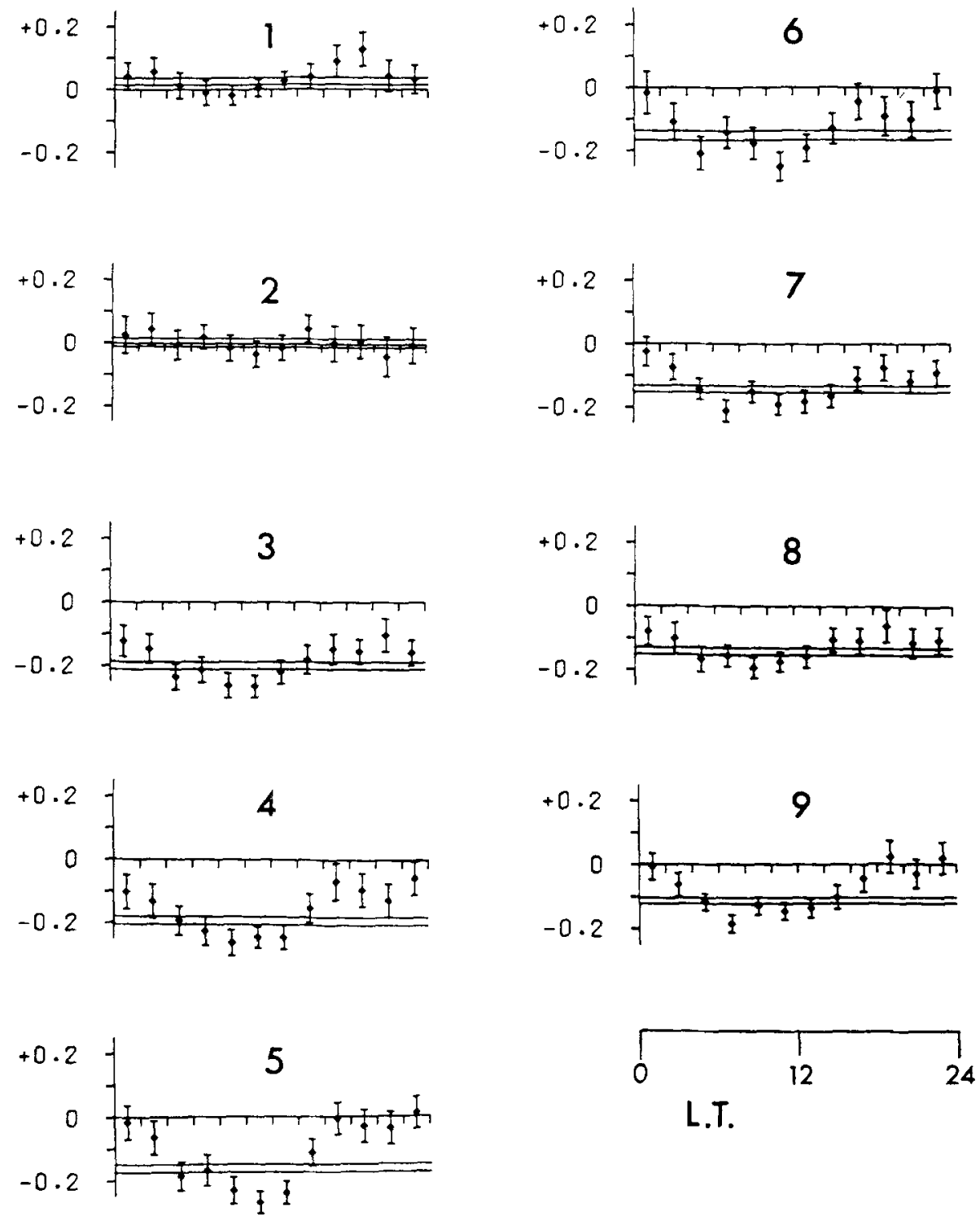

Fig. 7b. Real part of transfer function $A$ as a function of local time (LT) for 9 stations in Northern England, for period band B16: 60-40 s. Successively numbered stations are $10 \mathrm{~km}$ apart. Error bars are 4 s.d. 


\section{Observations of Time Variations in Response Functions}

In this Section we review some of the observed time-variations in electromagnetic response functions and note some of the difficulties and successes encountered. We first consider controlled source monitoring of resistivity $\rho$ beneath potential electrodes using current insertion from current electrodes. The method is direct since $\rho=V / I$ and little or no processing of the data is required.

\subsection{CONTROLLED SOURCE}

Rikitake (1976b) reports on the work of the Earthquake Research Institute (Tokyo) into in-situ and laboratory work on resistivity monitoring and measurement. Yamazaki (1967) constructed a sensitive null resistivity monitor using $I=100 \mathrm{~mA}$ at $f=67 \mathrm{~Hz}$. The system is capable of monitoring a change in resistivity of the order of 1 part in $10^{4}$. Over several years of observation some 30 or so examples of resistivity steps associated with earthquake occurrence have been observed. An example is shown in Figure 8 of a step associated with an earthquake $(M=7.9)$ at an epicentral distance of over $700 \mathrm{~km}$. The electrodes are set up across partially saturated tuff which appears to act as an amplifier of linear strain. The observed gains $(\Delta \rho / \rho / \Delta L / L)$ are in the range 2000 to 10000 . The reason why the rock exhibits such behaviour is not understood since laboratory studies on these tuffs show amplification factors not exceeding 400 (Madden, 1980).

An intensive program of observations has been conducted in the Garm region of the U.S.S.R. (Barsukov, 1972; Barsukov and Sorokin, 1973). The array consists of a current dipole using pulses of $100 \mathrm{~A}$ which are received $6 \mathrm{~km}$ away at potential electrodes. The re-

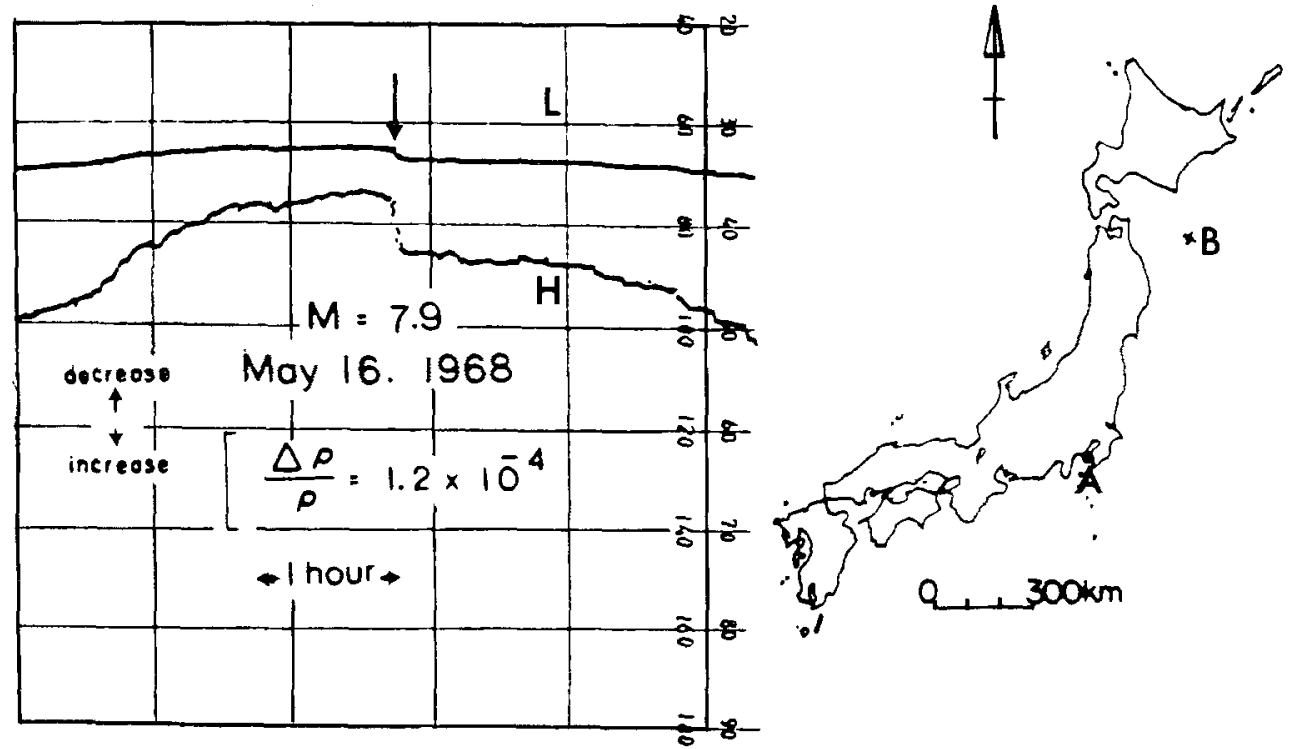

Fig. 8. Resistivity step concurrent with the Tokachi-oki earthquake, Japan $(M=7.9)$ as recorded by high $(H)$ and low $(L)$ sensitivity channels. The observation point is at A and the earthquake epicentre is at $B$ (after Rikitake and Yamazaki, 1970). 


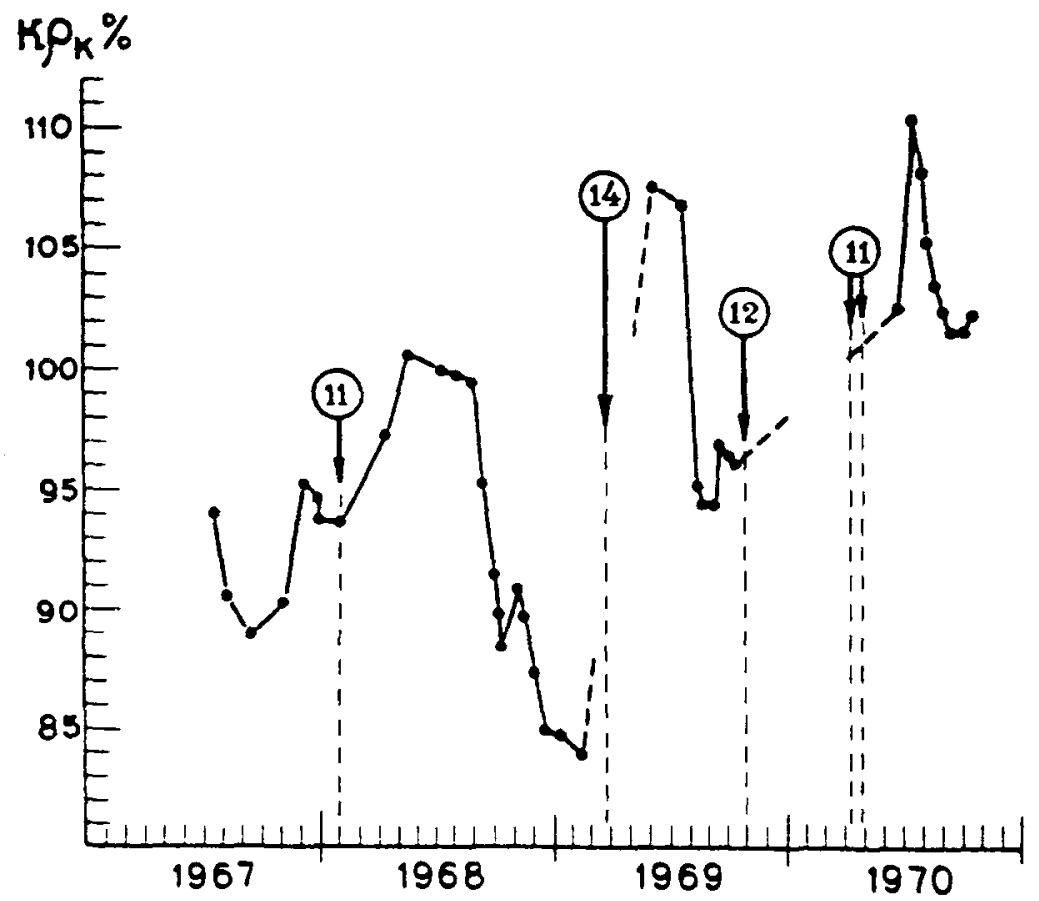

Fig. 9. Variation of apparent resistivity in one of the epicentral zones of the Garm region of the U.S.S.R. Strong earthquakes ( $K$ values in circles) appear after a minimum in apparent resistivity (after Sadovsky et al., 1972).

lative variations in resistivity observed over 4 yrs are shown in Figure 9 in relation to the strength and occurrences of local earthquakes which tend to occur along thrust faults. It is apparent that resistivity decreases of $10-15 \%$ are observed prior to moderately large earthquakes. Mazzella and Morrison (1974) report on electrical resistivity variations associated with earthquakes along the strike-slip San Andreas Fault. A set of 3 potential electrodes receive at distances of up to $15 \mathrm{~km}$ from the source current dipole. The source is $I=200$ A at $f=0.1 \mathrm{~Hz}$. Their normalised resistivity data show decreases in resistivity of 10-20\% prior to earthquakes associated with the San Andreas Fault.

\subsection{TELLURIC CURRENTS}

This section considers a few reports of changes in earth currents in which no reference or cancellation system is employed. The observations therefore monitor the natural telluric field variations (both inducing and induced) and have to detect anomalous internal effects above this background. Rikitake (1976b) gives an account of some historical observations. Bennett et al. (1977) describe telluric current observations in China prior to the Haicheng $(M=7.3)$ earthquake. The systems consist of 2 electrodes of different materials (e.g. $\mathrm{Cu}$ bar and $\mathrm{Pb}$ plate) with a horizontal separation of 30-60 m. The systems monitor I in microamps across a $10 \mathrm{k} \Omega$ resistor. Figure 10 shows the recording of one such system for 3 months prior to the Haicheng earthquake which occurred along strike-slip faults. The 


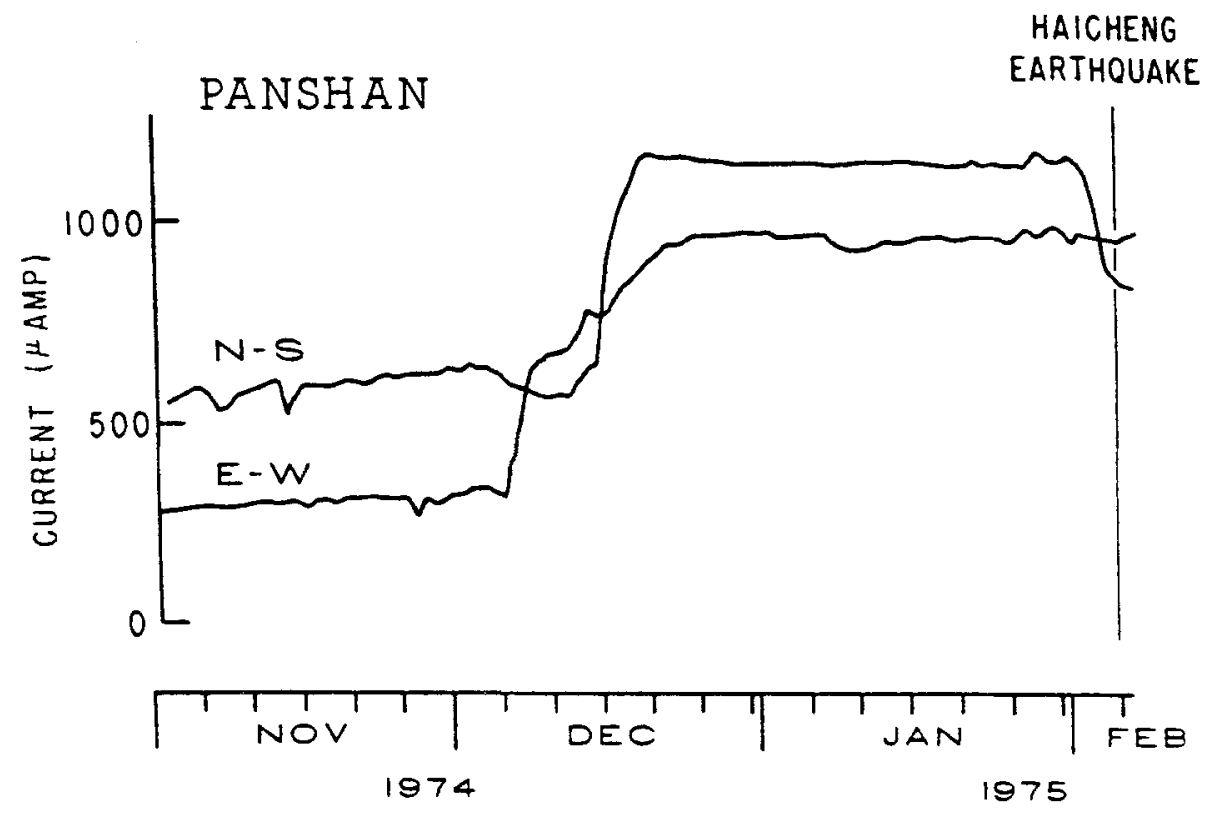

Fig. 10. Daily averages of hourly readings of current between N-S and E-W electrode pairs $(60 \mathrm{~m}$ separation) as reported by Amateur Group 2 at Panshan, China $(90 \mathrm{~km}$ from the epicenter of the Haicheng earthquake), (from Bennett et al., 1977).

$500 \mu$ amp change through the $10 \mathrm{k} \Omega$ resistor implies a $5 \mathrm{~V}$ change in potential difference over the $60 \mathrm{~m}$ separation.

An intensive study of anomalous changes in telluric currents has been undertaken in the Kamchatka subduction zone (Fedotov et al., 1970; Myachkin et al., 1972). After noise elimination procedures were adopted (Myachkin et al., 1972), local anomalous variations of telluric fields were determined before earthquakes with a magnitude $M \geqslant 4.5$. The anomalies were registered on 1,2 or 3 close stations located not further than $150 \mathrm{~km}$ from the epicentres of the earthquakes. Figure 11 shows some of the low pass filtered plots of the time variations observed. The hypocentres of the earthquakes causing such effects appear to occur in a restricted depth range of from $20-60 \mathrm{~km}$. Shallower and deeper events produce no observable effect. Myachkin et al. (1972) suggest: "This phenomena supposedly has a piezoelectric nature. The characteristic bay form of the anomalies can be caused by sharp acceleration of deformation processes in the source zone and then by their retardation before the earthquake occurrence".

Sobolev (1975) also reports on telluric currents as short-term precursors in Kamchatka. $\mathrm{He}$ notes "In the majority of cases, the changes of electrotelluric field before an earthquake do not exceed the background noise", (i.e. induced current variations). "This makes it impossible to distinguish precursors through the recording of one measuring line. As a result, standardization of methods is needed to conduct the joint processing of several synchronous records". Figure 12 shows an example of the recognition of anomalous changes by computer analysis (programs 1 and 2) of the unprocessed records of 4 telluric 


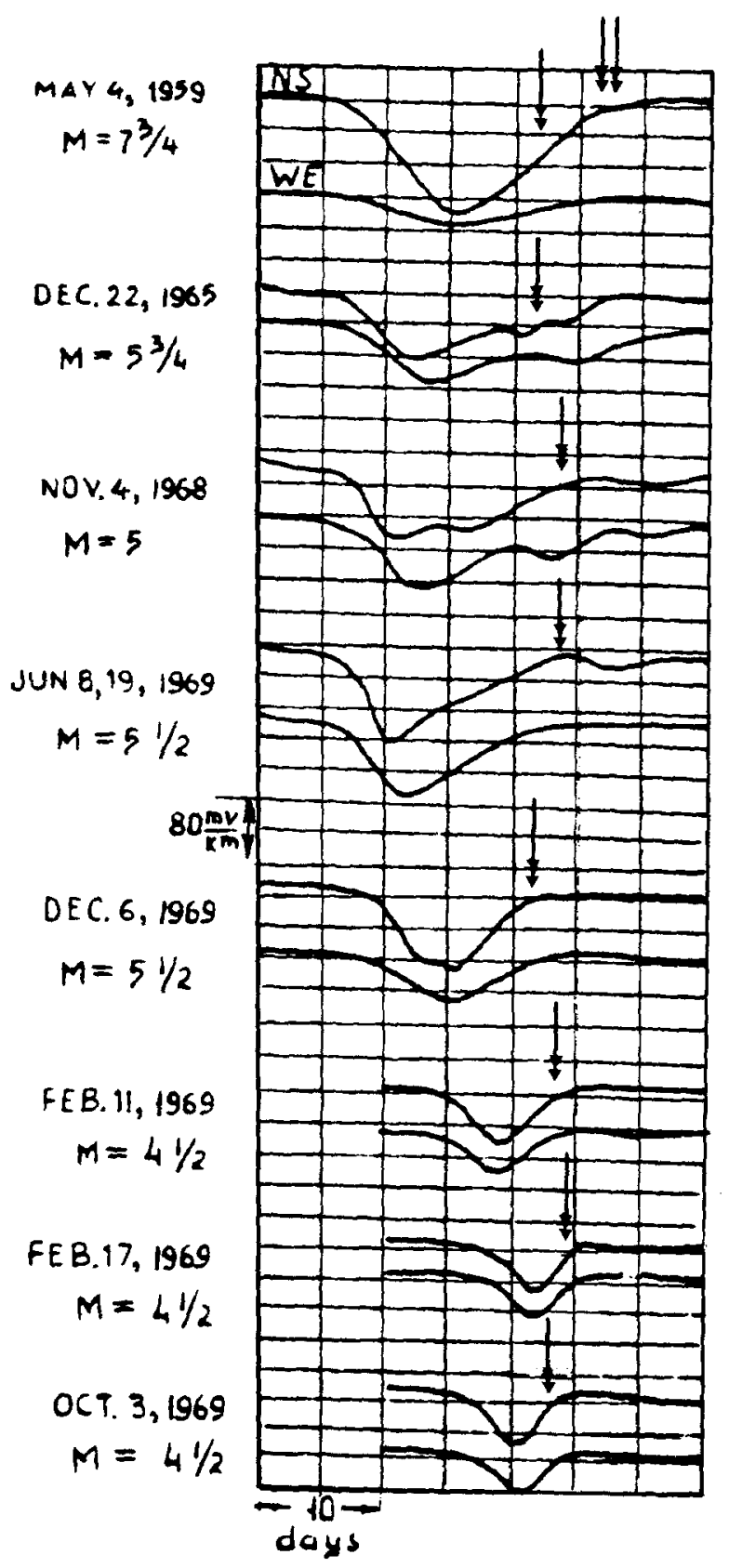

Fig. 11. The filtered telluric field observed before some earthquakes (indicated by arrows) at a coastal site in Kamchatka, U.S.S.R. The majority of forerunners have an amplitude of $100-300 \mathrm{mv}$ $\mathrm{km}^{-1}$ and a bay-like form (after Myachkin et al., 1972). 


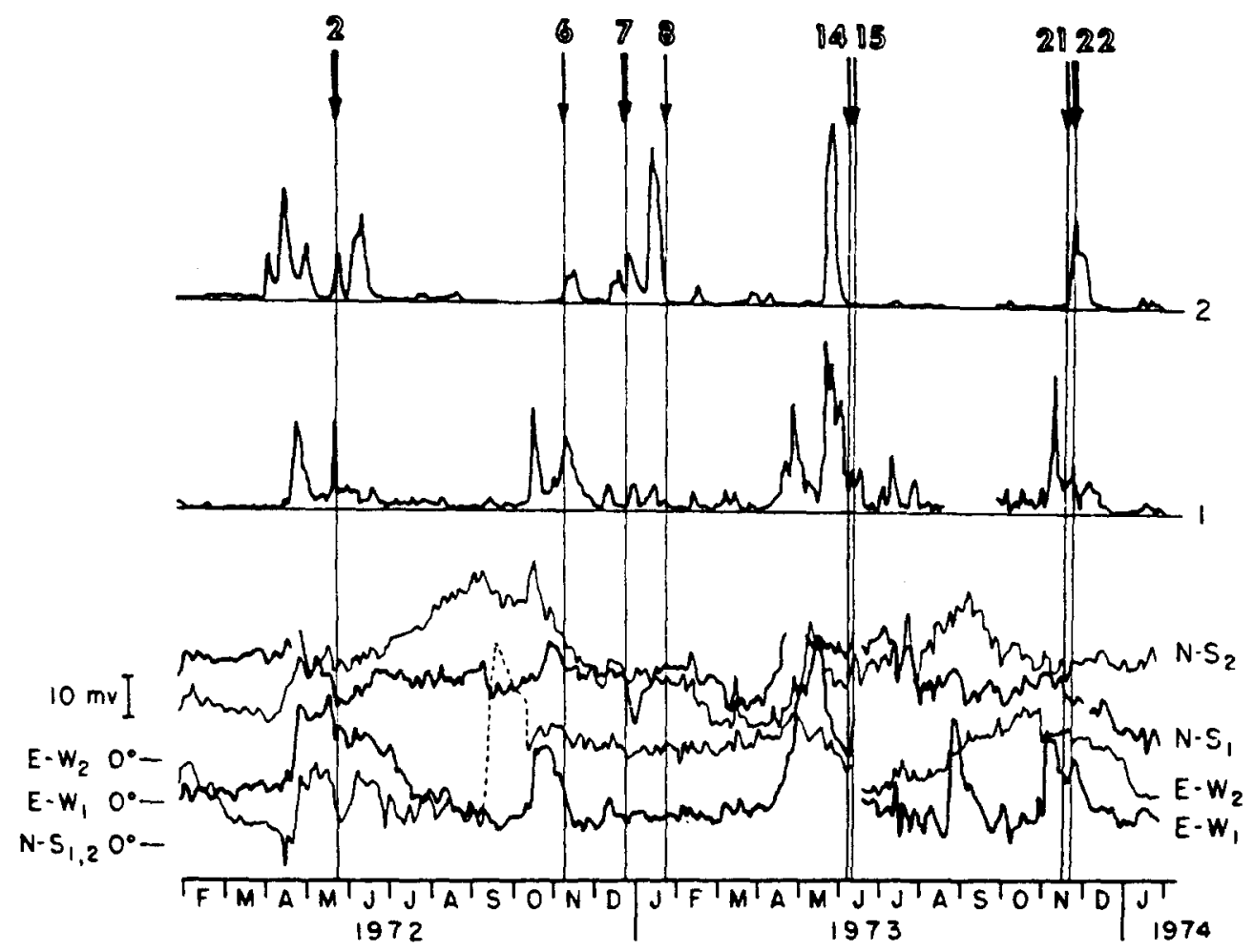

Fig. 12. Detection of earthquakes in Kamchatka, U.S.S.R. by 2 computer programs. Raw data from main and doubling N-S and E-W electrodes is also shown. The numbered arrows refer to earthquakes occurring with $M \geqslant 5.5$ (from Sobolev, 1975).

components ( $E-W, N-S$ : main and doubling lines) in central Kamchatka. The arrows show the earthquakes with magnitude $M>5.5$ that occurred closer than $250 \mathrm{~km}$ from the site. The results illustrate that most of the earthquakes were preceded by a detectable increase in the processed signal.

\subsection{DIFFERENTIAL ELECTRIC FIELD}

This is the equivalent telluric method to that of the differential magnetic method which detects the piezomagnetic effects of stress. The principal noise components are again the induced electromagnetic variation fields and in this case electrode potential variations (i.e. drift and electrochemical) can be an additional source of noise. Both can be reduced by synchronous detection schemes. Madden (1980) gives a thorough description of work at MIT in methodology and techniques. The following is a brief summary. The method uses the fact that the telluric ratios at low frequencies depend on the integrated conductivity of the crust beneath the recording dipoles. The telluric field differences should therefore be independent of the frequency content and the wavelengths of the inducing fields. The tensor nature of the induced electric field can be acknowledged by obtaining the differences between 3 sets of potential electrodes. Such a telluric cancellation system essentially 
monitors time changes in $\partial E / \partial x$ and therefore monitors changes in effective anisotropy of the resistivity beneath the dipole configuration. Noise elimination has been the main feature of the work and it is hoped to achieve a sensitivity of $\sim 0.03 \%$ (typically $<1 \mathrm{mV}$ $\mathrm{km}^{-1}$ ) which should be sufficient to detect some of the low stress regime effects noted in Section 2.2. Since the high sensitivity system is measuring tensor telluric field differences, the system should also be capable of detecting the purely electric effects of the electrokinetic process (Section 2) and hence be capable of monitoring pore pressure variations beneath the recording dipoles.

\subsection{SiNGLE-STATION GEOMAGNETIC TRANSFER FUNCTION}

Observations of the time variations in the response functions defined in Section 3 are now discussed. Many of these observations were considered by Niblett and Honkura (1980).

Yanagihara (1972) studied annual mean changes of $(A, B)$ over a $70 \mathrm{yr}$ interval at Kakioka observatory in Central Japan. The earlier scalar analysis was repeated by Shiraki and Yanagihara (1977) who calculated $(A, B)$ from magnetic storms by spectral analysis. One storm record ( $24 \mathrm{~h}$ duration) was used each year and 10-yr running averages determined for a period of $60 \mathrm{~min}$. Their results are reproduced in Figure 13. The reason why the transfer function at Kakioka undergoes such a secular change is not understood nor whether the $20 \mathrm{yr}$ decrease prior to the 1923 Kanto earthquake $(M=7.9)$ is significant. The transfer function at $60 \mathrm{~min}$. period undoubtedly responds to the Central Japan

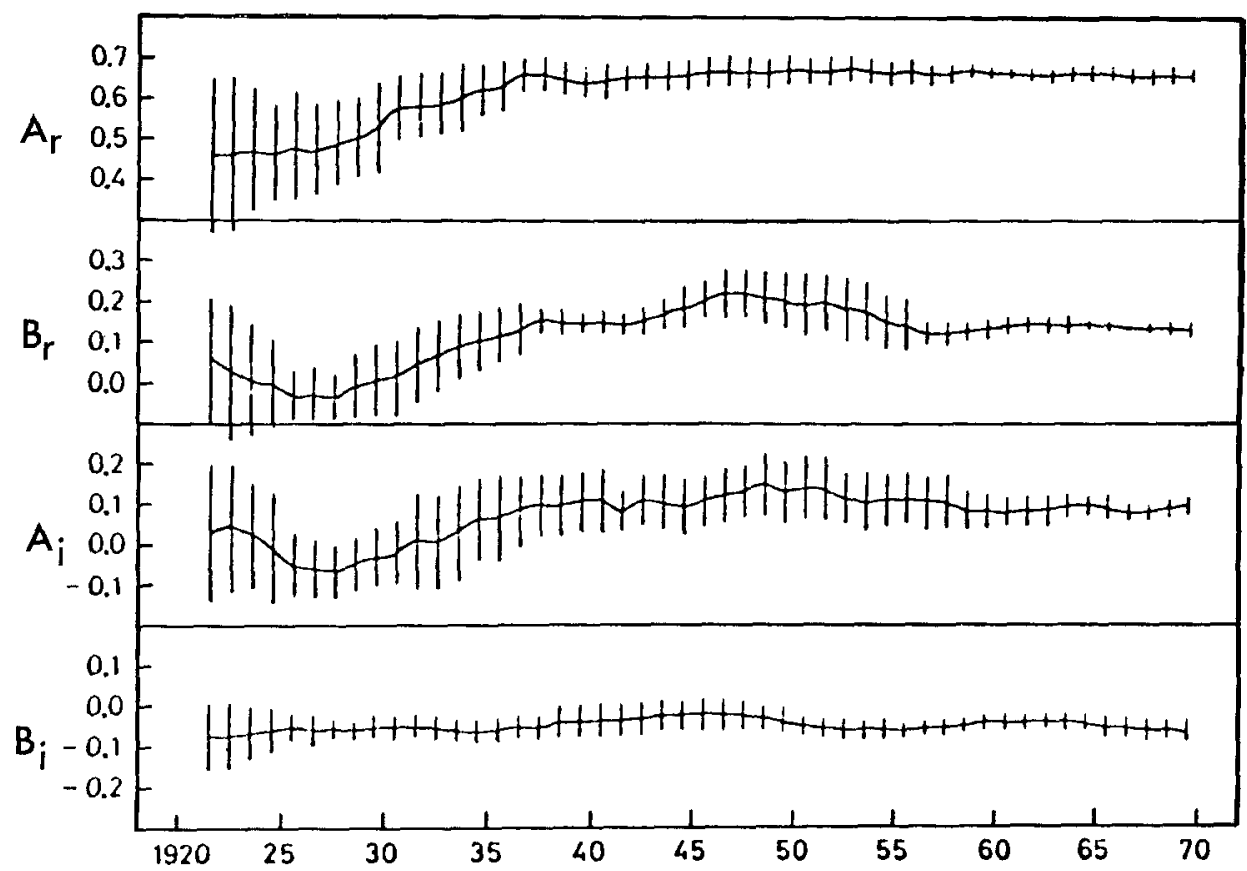

Fig. 13. Changes in real (Ar, Br) and imaginary $\left(A_{i}, B_{i}\right)$ parts of the transfer function at Kakioka, Japan for a period of 60 min obtained from 10-yr running averages. Error bars are $4 \mathrm{~s} . \mathrm{d}$. in length (from Niblett and Honkura, 1980; after Shiraki and Yanagihara, 1977). 
anomaly which, as interpreted by Rikitake (1969), consists of a depression of a highly conducting layer at mantle depths.

Niblett and Honkura (1980) quote the results of Miyakoshi (1975) who found a longterm $(5 \mathrm{yr})$ variation in the quantity $\left(A^{2}+B^{2}\right)^{1 / 2}$ at Tashkent. The variation of yearly mean values of $C$ reached a maximum value about $1 \mathrm{yr}$ prior to the Tashkent earthquake $(M=5.5)$ of 1966. No equivalent effect was found in $(A, B)$ when Miyakoshi analysed the magnetograms for Askhabad relative to the earthquake $(M=6.6)$ of 1970 . Yanagihara and Nagano (1976) studied the variation of $(A, B)$ at Kakioka observatory in greater detail than did Shiraki and Yanagihara (1977). They chose a number of isolated bay disturbances of period $\sim 80 \mathrm{~min}$. for some 22 months of data. No error determinations are given but the authors quote \pm 0.12 as the $95 \%$ confidence interval for the $80 \mathrm{~min}$. component produced by the analysis of 15 storms (Shiraki and Yanagihara, 1977). If the same result applies to the time variations observed by Yanagihara and Nagano (1976) then these cannot be considered significant.

Rikitake (1979a) investigated the transfer function determined from the magnetic records of Sitka observatory in Alaska from 1968 to 1973, encompassing the Sitka earthquake $(M=7.2)$ of 1972. Rikitake selected isolated events (associated with polar substorms) for half-yearly subperiods. The data base was between 35 and 51 events for each half year. The high geomagnetic latitude $\left(60^{\circ} \mathrm{N}\right)$ of Sitka results in standard errors of 25 and $9 \%$ in $A$ and $B$ respectively. The results showing the increase in $A$ about a year prior to the 1972 earthquake are reproduced in Figure 14. Rikitake acknowledges that the position of Sitka means that the data set is particularly sensitive to the effect of auroral zone currents even though the data set was selected to minimise such a contribution.

Honkura et al. (1976) describe preliminary results from a magnetotelluric station (Charlevoix) operated within a zone of localised seismicity in Quebec. In this preliminary study both impedance-tensor elements and geomagnetic transfer-functions were examined with regard to time-dependence in the period range 5-120 min. Although the impedance tensor elements exhibit a significant time-dependence (see Section 4.6) the corresponding component parts of $(A, B)$ showed no significant time variation.

\subsection{INTER-STATION TRANSFER FUNCTIONS}

There exist very few reports of the study of time variations in the inter-station transfer functions of Equations (3). Niblett and Honkura (1980) quote unpublished work undertaken by Honkura in Japan.

\subsection{MAGNETOTELLURIC RESPONSE FUNCTIONS}

Reddy et al. (1976) describe MT measurements in southern California. As noted in Section 3.2, the authors have modelled the anticipated changes in apparent resistivity due to a dilatancy process at the 3 monitoring sites. The authors present results in terms of rotated apparent resistivities in the period band $20-30$ s for some 8 months of recording. The dimensionality coefficients for all sites are small indicating 2-D structure. The anti- 

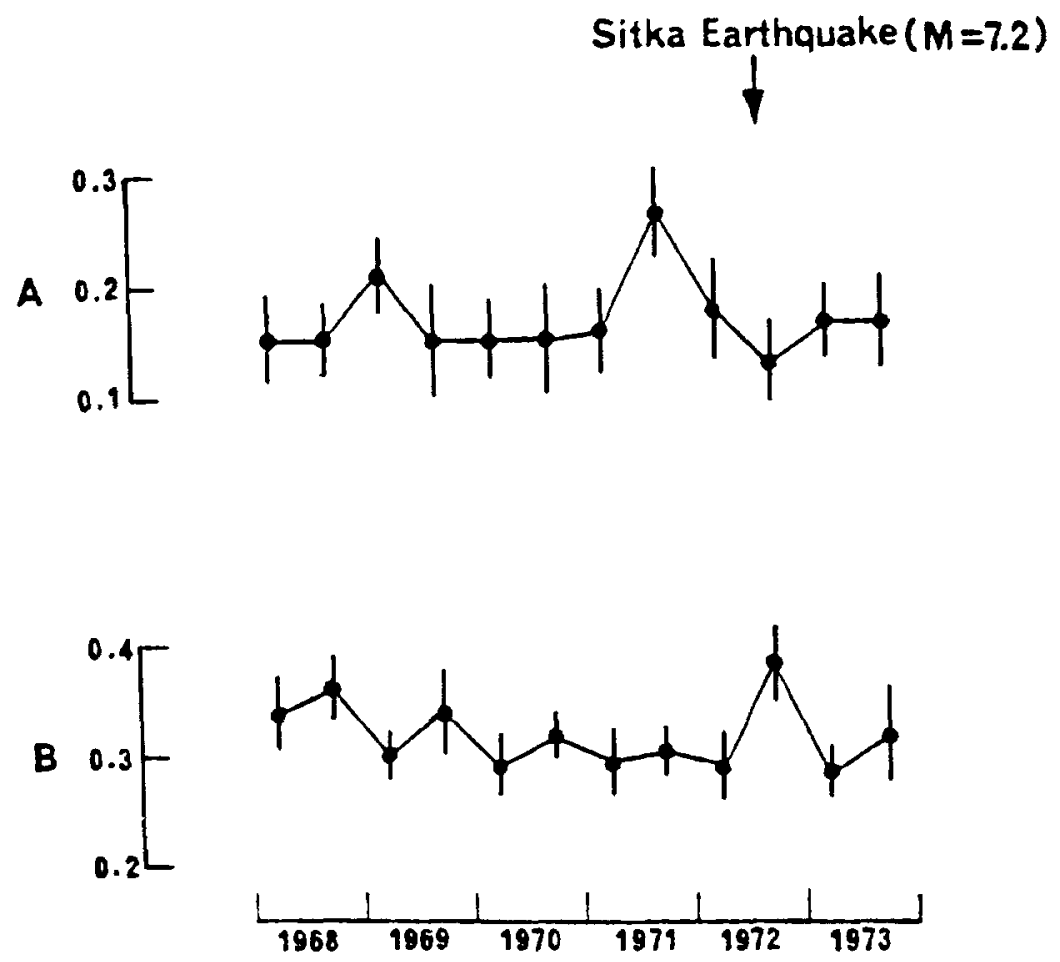

Fig. 14. Changes in the transfer function $(A, B)$ at Sitka, Alaska for short period ( $\sim 600 \mathrm{~s})$ variations obtained from data in half-yearly intervals. Error bars are 2 s.d. in length (from Rikitake, 1979a).

cipated change in rotated apparent resistivities at 2 of the sites is $\sim 50 \%$ in the $20-30 \mathrm{~s}$ band. Reddy et al. (1976) show that observed variations of between 10 and $20 \%$ can be accounted for by the biases introduced by changes in multiple coherencies (i.e. changes in noise levels) on the different channels. The authors conclude that no significant changes occurred during the first 8 months of recording although no earthquakes of magnitude $M>4$ occurred in the vicinity.

Kurtz and Niblett (1978) give an extended account of the time dependence of magnetotelluric response functions in Quebec. They describe results from 5 magnetotelluric stations and indicate that with the procedures used some 17 days of continuous recording are required to produce reliable estimates of the impedence tensor. Due to the complex geology of the region all the sites possess moderate to large dimensionality coefficients. A series of magnetotelluric response functions for over $2 \mathrm{yrs}$ of data are presented at 300 and $600 \mathrm{~s}$ period. Significance tests were applied to the variations and it was found that only the variations at one station (Charlevoix) could be considered significant. Much of the variation at Charlevoix is caused by a trend of $14 \%$ per year which the authors suggest may be caused by seasonally changing conditions in the nearby St. Lawrence River. Superimposed on the linear trend are significant non-linear variations suggesting that crustal resistivity is changing in response to the more or less continuous crustal instability of the region. 


\section{Correlations of the Time Variations of Response Functions}

It seems clear from the above studies that the active measurements of resistivity have observed the largest and most unambiguous variations in crustal resistivity. Two of these studies (Barsukov and Sorokin, 1973; Mazella and Morrison, 1974) have a clear affinity with the dilatancy-diffusion mechanisms proposed by Scholz et al. (1973). An important aspect of this mechanism is that precursor times appear closely correlated with the magnitude of the impending earthquakes as shown in Figure 15. The logarithm of the 5 different precursory duration times (crustal movement, radon emission, $V p / V s$ anomaly, $\Delta F$ and electrical resistivity) for more than 30 earthquakes seems to correlate with the ultimate magnitude of the earthquake suggesting a common physical mechanism for each of the observed anomalies. If the above effect is viewed solely as a manifestation of a

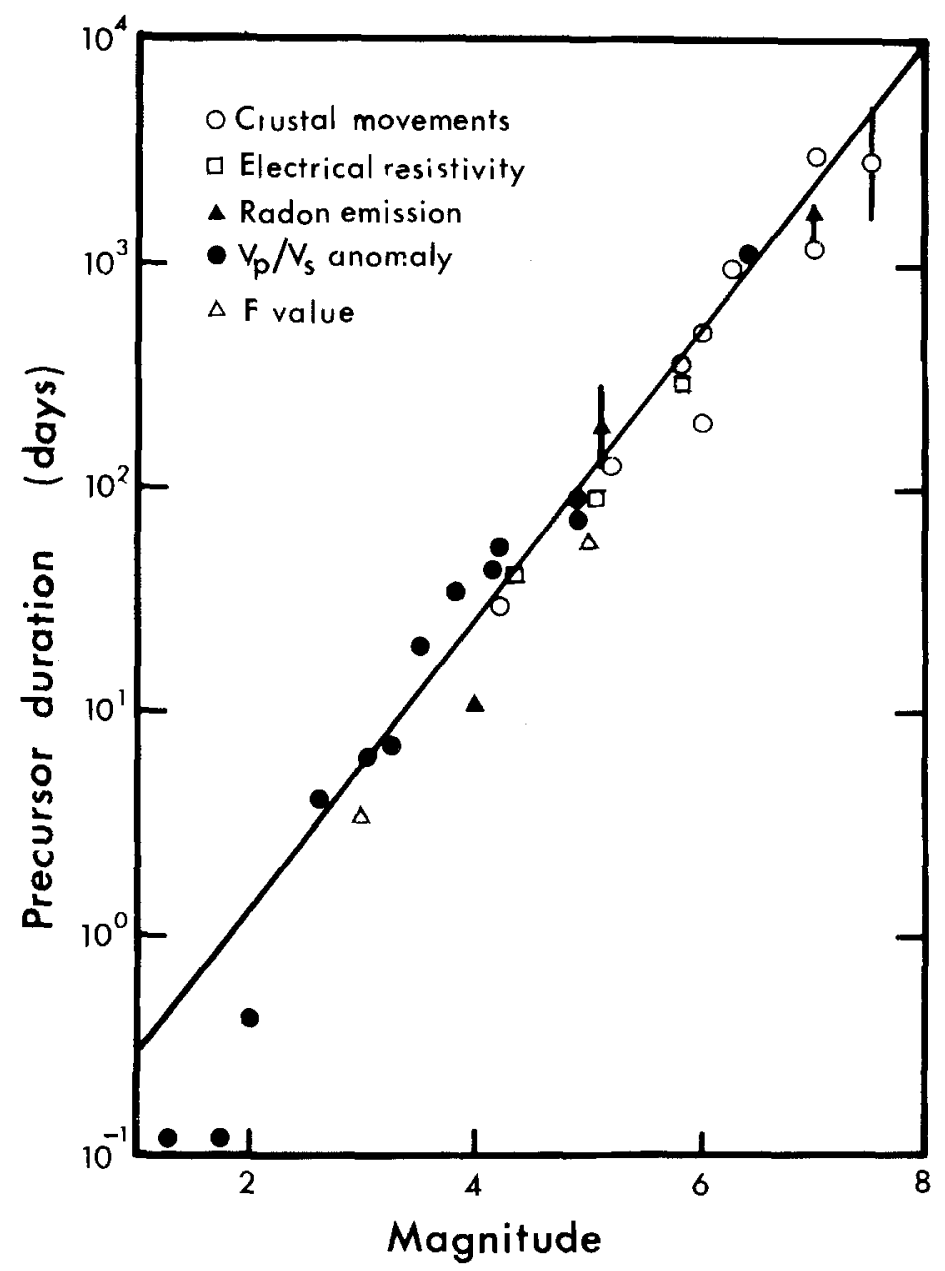

Fig. 15. Time interval (duration after onset) of various precursory phenomena as a function of earthquake magnitude (after Scholz et al., 1973). The electrical resistivity data are all taken from the controlled source data obtained in the Garm region, U.S.S.R. (see Barsukov and Sorokin, 1973). 
dilatancy process then it appears from the work of Rikitake (1976b) that dilatancy phenomena are to be associated with earthquake mechanisms across a very wide tectonic framework. Rikitake (1979b) considers nearly 400 observations, from some 19 different types of earthquake precursor and obtains the relationship

$$
\log _{10} T=0.6 \mathrm{M}-1.01 \text {. }
$$

The data set is taken from very different tectonic environments mainly in the Peoples Republic of China, Japan, the U.S.A. and the U.S.S.R. Both Rikitake (1979b) using empirical evidence, and Brady (1976), considering models of the inclusion theory of rock failure, indicate that observed precursors can be classified into 3 kinds. Class I precursors are long term, of the type discussed above, and are therefore to be associated with dilatancy. Class II precursors refer to short term indicators of failure, preceding the earthquake by a few days or hours. Changes in far-field stresses, such as tidal effects, are shown by Brady (1976) to be of particular importance in initiating Class II precursors. Class III precursors precede the earthquake by a matter of seconds.

Care must be exercised when relating resistivity changes to the dilatancy model since changes in seismic velocities $\left(V p / V_{s}\right)$ can also be accounted for by a dry dilatancy model, ie without fluid diffusion (Stuart, 1974; Brady, 1974). The differences in terms of resistivity variations between the wet and dry models of dilatancy are clearly considerable. Myachkin et al. (1975) discuss methods of differentiating between the possible wet and dry mechanisms of dilatancy. In addition we should acknowledge that there can be a total absence of any precursory phenomena in some shallow earthquakes (Kerr, 1979). We should also in our studies contrast deep earthquakes such as those occuring in subduction zones and shallow events since in the view of Dzeiwonski and Gilbert (1974) earthquakes occur through the lubrication of a fault plane. For shallow events, lubrication may indeed occur via a dilatancy diffusion mechanism. However, for deep events, lubrication may arise from local melting along the fault plane itself.

With regard to Class II and III precursors, both have been observed by the controlled source resistivity meter of Yamazaki (Yamazaki, 1975; Rikitake and Yamazaki, 1979) and in the telluric current observations in the Peoples Republic of China (Bennett et al., 1977). Clearly the processing of the larger quantities of data required for other reponse functions precludes observations of this kind. In addition to these precursory type effects we should also pay due regard to the long-term studies of resistivity variations that amount to ongoing tectonomagnetic experiments. The works of Madden (1980) and Kurtz and Niblett (1978) are examples of this kind. Work currently in progress in Quebec is exploring the correlations between time-variations in impedance elements and variations in seismic travel times, tilt and water levels. It appears that the results will ultimately reveal the nature of the crustal response to long-term stress accumulation rather than unambiguous precursory phenomena (Niblett, 1980, personal communication). 


\section{Discussion}

When considering the existing laboratory data on the effects of stress on electrical resistivity we should bear in mind that studies of jointed and fractured rock, typical of a fault zone, are only just being initiated. We must, at present, infer the behaviour of such rocks from the studies of competent igneous, metamorphic and sedimentary rocks.

Low stress-level changes produce only small percentage changes in resistivity. Large $(10 \%)$ decreases in resistivity occur with the onset of dilatancy in competent laboratory samples. The dilatancy-diffusion mechanism is seen to account for a wide variety of precursory phenomena (including resistivity and earth currents) from a wide variety of tectonic sites. With the associated increase in pore volume and permeability associated with dilatancy we could anticipate even larger $(>10 \%)$ decreases of in-situ resistivities due to large scale fluid diffusion from non-dilatant country rock. If this is the case, then examination of electromagnetic difference fields (and associated response functions) from sites within and outside the dilatant zone offer a means of monitoring the dilatancydiffusion process. The obvious proviso is that we use instrumentation which is sufficiently sensitive (see below).

The size of a dilatant region is a matter of some debate. Dobrovolsky et al. (1979) consider a circle of effective manifestation of precursory phenomena, centred on an epicentre, to be:

$$
r=10^{0.43 M}
$$

This estimate is to be compared with the precursor region size determined by Rikitake (1975) to be:

$$
r=10^{(0.51 M-2.27)} \quad(\mathrm{km})
$$

These formulae relate to the maximum area in which co-seismic crustal deformation can be observed. Scholz et al. (1973) consider that the dilated region can be considerably larger than that predicted by the above. Nur (1975) considers that when fault creep precedes failure then the dilatant volume can either increase with time (crack dilatancy) or decrease with time (joint dilatancy).

The onset of dilatancy in competent laboratory samples occurs at between 1- and 2thirds of the fracture stress. Clearly we would like to know the stress levels at depth. However, acceptable approaches to stress measurement at depth are still being explored (Jamison and Cook, 1980).

We should note that, in general, the observations used in deriving geomagnetic transfer functions have not been from designed field studies. Investigators have tended to use the data from an appropriately situated magnetic observatory. Considering the problems associated with these response functions we should acknowledge that the monitoring of the time dependance of lateral concentrations of current, using single station transfer functions, are at best a second-order effect of most of the stress-induced effects considered here. As mentioned above, for time dependent studies an appropriate method is to 
estimate $\left(H_{X}^{a}, H_{Y}^{a}, H_{Z}^{a}\right.$ ) from difference fields, i.e. $H^{a}=H^{S}-H^{R}$ where $H^{S} . H^{R}$ are field components recorded at 2 sites $S$ and $R$ (see for example, Babour and Mosnier, 1977). Although difficulties of interpretation can arise over the choice of a reference site $R$ when local currents exhibit a marked phase variation with respect to regional currents, the method is capable of removing source field ambiguities within the data set. When both $S$ and $R$ are influenced by the same current concentration, the method should allow time changes in the gradient of the anomalous field to be monitored.

The situation with regard to the time dependence of magnetotelluric response functions largely concerns the accuracy with which a particular response function can be determined. Typically, active resistivity measurements (e.g. Mazella and Morrison, 1974) quote a standard error of $1 \%$ while passive experiments (e.g. Reddy et al., 1976) quote a standard error of $10 \%$ in rotated tensor impedances. Both the remote reference methodology of Gamble et al. (1979) and the differential electric field measurements of Madden (1980) are worth considering if a sensitive field monitoring system is under consideration.

We should also keep in mind that electromagnetic soundings integrate the effects of the induced distribution of fields within the skin-depth volume. To observe time variations of crustal resistivity using passive techniques we should ideally sound localised crustal volumes using high frequency (audio) bandwidths. Several groups have turned to the high frequency mode of sounding in order to obtain strategic information at shallow $(0-5 \mathrm{~km})$ crustal depths (e.g. Hoover et al., 1976; Strangway, 1980). These high resolution soundings, applied within the context of geothermal and toxic waste disposal programs, should ultimately provide the ability to monitor some of the smaller-scale (though none the less important) time dependent crustal processes here considered.

\section{References}

Anderson, C. W., Lanzerotti, L. J., and Mactennan, C. G.: 1978, 'Local Time Variation of Geomagnetic Induction Vectors', J. Geophys. Res. 83, 3469-3484.

Babour, K. and Mosnier, J.: 1977, 'Differential Geomagnetic Sounding', Geophysics 42, 66-76.

Barsukov, O. M.: 1972, 'Variations of Electrical Resistivity of Mountain Rocks Connected with Tectonic Causes', Tectonophysics 14, 273-277.

Barsukov, O. M. and Sorokin, O. N.: 1973, 'Variations in Apparent Resistivity of Rocks in the Seismically Active Garm Region', Izv. Acad. Sci. U.S.S.R. (Phys. Solid Earth) 8, 685-687.

Beamish, D.: 1979, 'Source Field Effects on Transfer Functions at Mid-latitudes', Geophys. J. Roy Astr. Soc. 53, 117-134.

Beamish, D.: 1980, 'Diurnal Characteristics of Transfer Functions at Pulsation Periods', Geophys. $J$. Roy. Astr. Soc. 61, 623-643.

Bendat, J. S. and Piersol, A. G.: 1971, Random Data: Analysis and Measurement Procedures, J. Wiley and Sons, New York.

Bennett, G., Craig, H., Hanks, T., Molnar, P., Nur, A., Raleigh, B., Savage, J., Scholz, C., Turner, R., and Wu, F.: 1977, 'Prediction of the Haicheng Earthquake', EOS 58, 236-272.

Brace, W. F.: 1972, 'Pore Pressure in Geophysics', in Heard, H. C., Borg, I. Y., Carter, N. L., and Raleigh, C. B. (eds.), Flow and Fracture in Rocks, Geophys. Mon. 16, AGU Washington.

Brace, W. F.: 1978, 'A Note on Permeability Changes in Geologic Material Due to Stress', Pure and Appl. Geophys. 116, 627-633.

Brace, W. F., Orange, A. S., and Madden, T. R.: 1965, 'The Effect of Pressure on the Electrical Resist- 
ivity of Watersaturated Crystalline Rocks', J. Geophys. Res. 70, 5669-5678.

Brace, W. F. and Orange, A. S.: 1966, 'Electrical Resistivity: Changes in Saturated Rock Due to Stress', Science 153, 1525-1526.

Brace, W. F. and Orange, A. S.: 1968, 'Electrical Resistivity Changes in Saturated Rocks During Fracture and Frictional Sliding', J. Geophys. Res. 73, 1433-1445.

Brady, B. T.: 1974, 'Theory of Earthquakes - I. A Scale Independent Theory of Rock Failure', Pure and Appl. Geophys. 112, 701-726.

Brady, B. T.: 1976, 'Theory of Earthquakes - IV. General Implications for Earthquake Prediction', Pure and Appl. Geophys. 114, 1031-1082.

Dobrovolsky, I. P., Zubkov, S. I., and Miachkin, V. I.: 1979, 'Estimation of the Size of Earthquake Preparation Zones', Pure and Appl. Geophys. 117, 1025-1044.

Dziewonski, Z. M. and Gilbert, F.: 1974, 'Temporal Variation of the Seismic Moment Tensor and the Evidence of Precursive Compression for Two Deep Earthquakes', Nature 247, 185-188.

Everett, J. E. and Hyndman, R. D.: 1967, 'Geomagnetic Variations and Electrical Conductivity Structure in South-western Australia, Phys. Earth Planet. Int. 1, 24-34.

Fedotov, S. A., Dolbilkina, N. A., Morozov, V. N., Myachkin, V. I., Preobrazhensky, V. B., and and Sobolev, G. A.: 1970, 'Investigation on Earthquake Prediction in Kamchataka', Tectonophysics 9, 249-258.

Fitterman, D. V.: 1979, 'Theory of Electrokinetic Magnetic Anomalies in a Faulted Half-space' $J$. Geophys. Res. 84, 6031-6040.

Gamble, T. D., Goubau, W. M., and Clarke, J.: 1979, 'Error Analysis for Remote Reference Magnetotellurics', Geophysics 44, 959-968.

Goodman, N. R.: 1965, Measurement of Matrix Frequency Response Functions and Multiple Coherence Functions, Technical Report AFFDL-TR-65-56, Wright-Patterson Air Force Base, Ohio.

Honkura, Y.: 1976, 'Perturbation of the Electric Current by a Resistivity Anomaly and Its Application to Earthquake Prediction', J. Geomag. Geoelectr. 28, 47-57.

Honkura, Y., Niblett, E. R., and Kutz, R. D.: 1976, 'Changes in Magnetic and Telluric Fields is a Seismically Active Region of Eastern Canada: Preliminary Results of Earthquake Prediction Studies, Tectonophysics 34, 219-230.

Hoover, D. B., Frischknecht, F. C., and Tippens, C. L.: 1976, 'Audiomagnetotelluric Sounding as a Reconnaissance Exploration Technique in Long Valley, California', J. Geophys. Res. 81, 801-809.

Jamison, D. B. and Cook, N. G. W.: 1980, "Note on Measured Values for the State of Stress in the Earth's Crust', $J$. Geophys. Res. 85, 1833-1838.

Kean, W. F., Day, R., Fuller, M., and Schmidt, V. A.: 1976, 'The Effect of Unaxial Compression on the Initial Susceptibility of Rocks as a Function of Grain Size and Composition of Their Constituent Titanomagnetites', J. Geophys. Res. 81, 861-872.

Kerr, R. A.: 1979, 'Prospects for Earthquake Prediction Wane', Science 206, 542-545.

Kurtz, R. D. and Niblett, E. R.: 1978, 'Time Dependence of Magnetotelluric Fields in a Tectonically Active Region in Eastern Canada', J. Geomag. Geoelectr. 30, 561-577.

Madden, T. R.: 1980, Electrical Measurements as Stress-strain Monitors, submitted as an USGS open file report.

Mersmann, U., Baumjohann, W., Kuppers, F., and Lange, K.: 1979, 'Analysis of an Eastward Electroject by Means of Upward Continuation of Ground-based Magnetometer Data', J. Geophys. 45, $281-298$.

Mizutani, H., Ishido, T., Yokokura, T., and Ohnishi, S.: 1976, 'Electrokinetic Phenomena Associated with Earthquakes', Geophys. Res. Letters 3, 365-368.

Miyakoshi, J.: 1975, 'Secular Variation of Parkinson Vectors in a Seismically Active Region of Middle Asia', J. Fac. General Education, Tottori Univ. 8, 209-218.

Myachkin, V. I., Brace, W. F., Sobolev, G. A., and Dieterich, J. H.: 1975, 'Two Models for Earthquake Forerunners', Pure and Appl. Geophys. 113, 169-181.

Myachkin, V. I., Sobolev, G. A., Dolbikina, N. A., Morozov, V. N., and Preobrazensky, V. B.: 1972, 'The Study of Variations in Geophysical Fields Near Focal Zones of Kamchatka', Tectonophysics 14, 287-293.

Nagata, T.: 1969, Tectonomagnetism, IAGA Bulletin No. 27, 12-43.

Niblett, E. R. and Honkura, Y.: 1980, "Time-dependence of Electro-Magnetic Transfer Functions and 
Their Association with Tectonic Activity', Geophys. Surv. 4, 97-114.

Nulman, A. A., Shapiro, V. A., Maksimovskikh, S. I., Ivanov, N. A., Kim, J., and Carmichael, R. S.: 1978, Magnetic Susceptibility of Magnetite Under Hydrostatic Pressure, and Implications for Tectonomagnetism', J. Geomag. Geoelectr. 30, 585-592.

Nur, A.: 1972, 'Dilatancy, Pore Fluids, and Premonitory Variations of $t s / t p$ Travel Times', Bull. Seism. Soc. Amer. 62, 1217-1222.

Nur, A.: 1975, 'A Note on the Constitutive Law for Dilatancy', Pure and Appl. Geophys. 113, 197206.

Quon, C., Vozoff, K., Hoversten, M., Morrison, H. F., and Lee, K-H.: 1979, 'Localised Source Effects on Magnetotelluric Apparent Resistivities', J. Geophys. 46, 291-299.

Reddy, I. K., Phillips, R. J., Whitcomb, J. H., Cole, D. M., and Taylor, R. A.: 1976, 'Monitoring of Time-dependent Electrical Resistivities by Magnetotellurics', J. Geomag. Geoelectr. 28, 165-178.

Rikitake, T.: 1969, 'The undulation of an Electrically Conductive Layer Beneath the Islands of Japan', Tectonophysics 7, 257-264.

Rikitake, T.: 1975, 'Dilatancy Model and Empirical Formulas for an Earthquake Area', Pure and Appl. Geophys. 113, 141-147.

Rikitake, T.: 1976a, 'Crustal Dilatancy and Geomagnetic Variations of Short Period', J. Geomag. Geoelectr. 28, 145-156.

Rikitake, T.: 1976b, 'Earthquake Prediction', Developments in Solid Earth Geophysics, Vol. 9, Elsevier.

Rikitake, T.: 1979a, 'Changes in the Direction of Magnetic Vector of Short-period Geomagnetic Variations before the 1972 Sitka, Alaska, Earthquake', J. Geomag. Geoelectr. 31, 441-448.

Rikitake, T.: 1979b, 'Classification of Earthquake Precursors', Tectonophysics 54, 293-299.

Rikitake, T. and Yamazaki, Y.: 1979, 'A Resistivity Precursor of the 1974 Izu-Hanto-Oki Earthquake', J. Phys. Earth 27, 1-6.

Sadovsky, M. A., Nersesov, I. L., Nigmatullaev, S. K., Latynina, L. A., Lukk, A. A., Semenov, A. N., Simbireva, I. G., and Ulomov, V. I.: 1972, 'The Processes preceding Strong Earthquakes in Some Regions of Middle Asia', Tectonophysics 14, 295-307.

Sbar, M. L., Engelder, T., Plumb, R., and Marshak, S.: 1979, 'Stress Pattern Near the San Andreas Fault, Palmdale, California, from Near-surface in Situ Measurements', J. Geophys. Res. 84, 156164.

Schmucker, U.: 1970, 'Anomalies of Geomagnetic Variations in the Southwestern United States', Bull. Scripps Institute of Oceanography 13.

Scholz, C. H., Sykes, L. R., and Aggarwal, Y. P.: 1973, 'Earthquake Prediction: A Physical Basis', Science 181, 803-810.

Shiraki, M. and Yanagihara, K.: 1977, 'Transfer Functions at Kakioka (part II) Reevaluation of Their Secular Changes', Mem. Kakioka Mag. Obs. 17, 19-25.

Simmons, G. and Richter, D.: 1976, Physics and Chemistry of Minerals and Rocks, Strens, R. G. J. (ed.), John Wiley and Sons, 105-137.

Sims, W. E., Bostick, F. N., and Smith, H. W.: 1971, 'The Estimation of Magnetotelluric Impedance Tensor Elements from Measured Data', Geophysics 36, 938-942.

Sobolev, G. A.: 1975, 'Application of Electric Method to the Tentative Short-term Forecast of Kamchatka Earthquakes', Pure and Appl. Geophys. 113, 229-235.

Srivastava, S. P.: 1965, Method of Interpretation of Magnetotelluric data When Source Field is Considered', J. Geophys. Res. 70, 945--954.

Stacey, F. D.: 1963, 'Seismomagnetic Effect and the Possibility of Forecasting Earthquakes', Nature $200,1803-1085$.

Stacey, F. D.: 1964, 'The Seismomagnetic Effect', Pure and Appl. Geophys. 58, 5-22.

Stacey, F. D., Barr, K. G., and Robson, G. R.: 1965, 'The Volcano-Magnetic Effect', Pure and Appl. Geophys. 62, 96-104.

Stacey, F. D. and Johnston, M. J. S.: 1972, 'Theory of the Piezomagnetic Effect in Titanomagnetitebearing Rocks', Pure and Appl. Geophys. 97, 146-155.

Strangway, D. W.: 1980, 'Geophysical Methods and Toxic Waste Disposal', Geoscience Canada 7, $30-32$.

Stuart, W. D.: 1974, 'Diffusionless Dilatancy Model for Earthquake Precursors', Geophys. Res. Letters $1,261-264$. 
Wang, Chi-Yuen, Goodman, R. E., Sundaram, P. N., and Morrison, H. F.: 1975, 'Electrical Resistivity of Granite in Frictional Sliding: Application to Earthquake Prediction', Geophys. Res. Letters 2, $525-528$.

Wang, Chi-Yuen, Sundaram, P. N., and Goodman, R. E.: 1978, 'Electrical Resistivity Changes in Rocks During Frictional Sliding and Fracture', Pure and Appl. Geophys. 116, 717-731.

Yamazaki, Y.: 1967, 'Electrical Conductivity of Strained Rocks' (3rd paper), 'A resistivity variometer', Bull. Earthquake Res. Inst., Univ. Tokyo, 45, 849-860.

Yamazaki, Y.: 1975, 'Precursory and Coseismic Resistivity Changes', Pure and Appl. Geophys. 113, 219.

Yanagihara, K.: 1972, 'Secular Variation of the Electrical Conductivity Anomaly in the Central Part of Japan', Mem. Kakioka Mag. Obs. 15, 1-11.

Yanagihara, K. and Nagano, T.: 1976, 'The Change of Transfer Function in the Central Japan Anomaly', J. Geomag. Geoelectr. 28, 157-163.

Yukutake, T. and Tachinaka, H.: 1967, 'Geomagnetic Variation Associated with Stress Change Within a Semi-infinite Elastic Earth Caused by a Cylindrical force', Bull. Earthquake Res. Inst., Univ. Tokyo 45, 785-798.

Zoback, M. D. and Roller, J. C.: 1979, 'Magnitude of Shear Stress on the San Andreas Fault: Implications of a Stress Measurement Profile at Shallow Depth', Science 206, 445-447. 